\title{
Electromagnetic and Physical Properties of Sea Ice Formed in the Presence of Wave Action
}

\author{
Robert G. Onstott, Member, IEEE, Prasad Gogineni, Senior Member, IEEE, Anthony J. Gow, \\ Thomas C. Grenfell, Associate Member, IEEE, Kenneth C. Jezek, Associate Member, IEEE, \\ Donald K. Perovich and C. T. Swift, Fellow, IEEE
}

\begin{abstract}
Estimating the magnitude of brine flux to the upper ocean requires an ability to assess the dynamics of the formation of sea ice in a region. Brine storage and rate of expulsion is determined by the environmental conditions under which the sea ice forms. In this paper, the physical and electromagnetic properties of sea ice, formed under wave-agitated conditions, are studied and compared with results obtained from ice formed under quiescent conditions. Wave agitation is known to have a profound effect on the air-ice interface and internal ice structure. A variety of sensors, both active and passive, optical and microwave, were used to perform this characterization. Measured electromagnetic parameters included radar backscatter, microwave emission, and spectral albedo in the visible and infrared. Measured physical properties included ice structure, brine and temperature distribution, profiles of the vertical height of the air-ice interface, and ice formation processes. Results showed that emission, backscatter, and albedo all take different signature paths during the transformation from saline water to young sea ice and that the paths depend on sea surface state during ice formation.
\end{abstract}

Index Terms - Backscatter, electromagnetics, emission, pancake ice, sea ice.

\section{INTRODUCTION}

$\mathbf{S}$ EA ICE that has recently formed is one of the most important ice categories. In polar regions, thin ice greatly influences the exchange of energy between the atmosphere and ocean, the dynamics of the perennial ice cover, the input of salt into the oceanic mixed layer, and the generation of oceanic bottom water [1], [2]. The areal coverage of thin ice in polar regions integrated over the annual cycle is large in both the Arctic (e.g., $8 \times 10^{6} \mathrm{~km}^{2}$ ) and the Antarctic (e.g., $16 \times 10^{6} \mathrm{~km}^{2}$ ). During winter in the Antarctic, the circumpolar ice margin is composed largely of pancake ice to $270 \mathrm{~km}$ from the ice edge, and it is the dominant southern ocean ice cover component [2]. Because of the significant loss

Manuscript received October 31, 1997; revised June 23, 1998. This work was supported by the Office of Naval Research as part of an accelerated research initiative on the electromagnetic properties of sea ice and NASA under Research Grants N00014-89-J-1140, 3352-PP-0112, and N00014-93-C0005 .

R. G. Onstott is with the Environmental Research Institute of Michigan, Ann Arbor, MI 48107 USA (e-mail: onstott@erim-int.com).

P. Gogineni is with the Department of Electrical Engineering, University of Kansas, Lawrence, KS 66045 USA.

A. J. Gow and D. K. Perovich are with the U.S. Army Cold Regions Research and Engineering Laboratory, Hanover, NH 03755 USA.

T. C. Grenfell is with the Department of Atmospheric Sciences, University of Washington, Seattle, WA 98195 USA.

K. C. Jezek is with the Byrd Polar Center, Ohio State University, Columbus, OH 43210-1002 USA.

C. T. Swift is with the Microwave Remote Sensing Laboratory, University of Massachusetts, Amherst, MA 01003 USA.

Publisher Item Identifier S 0196-2892(98)06661-3. of heat from the ocean to the atmosphere due to the presence of thin ice in polar regions, and the dynamics associated with regions that promote the production of thin ice, it is important to global environmental monitoring to develop an improved ability to assess the sea ice dynamics within these regions. Therefore, there is a need to utilize remote-sensing data to retrieve sea ice property and dynamics information. The monitoring of regions that are remote, hazardous, and dark a large part of the year as well as cover millions of square kilometers is only possible via satellite-based sensors. Hence, knowledge of the relationship between ice properties and electromagnetic signatures based on existing and future satellite technology is required. In this investigation, a wide range of sensor parameters are used to support the development of a "broad spectral approach" to the problem of inverting sensor signal data to sea ice form and profile properties. Previous work has concentrated largely on what may be retrieved by a sensor operating in a single portion of the electromagnetic spectrum. Ice type designations are based on World Meteorological Organization [3] and commonly used ice form terminology. The category of thin ice (thickness less than $30 \mathrm{~cm}$ ) includes frazil ice, grease ice, slush, shuga, ice rind, nilas, and pancake ice. The definitions for the ice forms that are important in this study follow.

Frazil Ice: Frazil Ice is the initial ice state, a suspension of fine spicules or platelets of ice in sea water, which forms on the sea surface in regions of high turbulence.

Grease Ice: Grease Ice is the freezing of frazil ice, in which the spicules and plates of ice have coagulated into a thick soupy layer on the water surface. Grease ice forms during windy conditions, often into streamers, and has a high enough viscosity to dampen out the capillary waves of the ocean surface.

Nilas: Nilas is a thin elastic crust of ice, easily bending in waves and swell.

Shuga: Shuga is the coagulation of grease ice into flocs or clumps of crystals, a few centimeters across.

Slush: Slush is used here to indicate a viscous floating mass of ice crystals.

Pancake Ice: Pancake ice is the accretion of pieces of shuga into elliptically or circularly shaped pans ranging in size from 10 to $100 \mathrm{~cm}$ across. The bumping of pans against one another forces the grease ice located between pans to pile onto the pans edges, forming rims on an otherwise flat pan. Pans form during freezing and wave-agitated conditions from grease ice, shuga, or the breakup of nilas. At the marginal ice 
zone, where swell waves may be quite large, multiple pans may adhere and bond together into large pan composites up to as much as $3 \mathrm{~m}$ in diameter, or until floes are formed whose diameters are on the order of $10 \mathrm{~m}$.

Oceanic regions of high turbulence and wave action include the open ocean, the marginal ice zone, or large leads in which gravity waves are generated by wind. Frazil and grease ice are produced in small leads, but shuga and pancake ice require large fetches and gravity waves. Waves will also prevent the formation of continuous sheets of newly formed ice. In addition, because of the filtering action of frazil and ice pans, high wave energy and long ocean wavelengths are required to form large ice pans, and pans formed under these conditions have more complex surfaces and internal structures. Pans, also referred to as pancakes, form where there is a large field of frazil ice. Polynyas often promote sea ice production and are areas that may comprise open water, streams of frazil and grease ice, and large fields of pans [1], [4], [5]. One example is the Odden Ice Tongue that is found in the East Greenland Sea [6].

A laboratory program was conducted during January 1995 to study sea ice formation when waves are present. Observations began with sea water at its freezing point and continued through the formation of frazil ice, slush, the formation of pans, and the consolidation of a field of pans into an ice sheet. The measurement series was concluded with observations of the ice sheet many days old. This work was conducted in an outdoor tank at the United States Army Cold Regions Research and Engineering Laboratory (CRREL), Hanover, $\mathrm{NH}$. A notable product resulting from this investigation is an integrated data set that is wavelength and sensor-type diverse. The electromagnetic spectrum ranges from optical to decimeter wavelengths. Sensor approaches include the following:

1) active and passive;

2) polarization diverse;

3) incidence angle diverse;

4) wavelength diverse.

In Section II of this paper is a summary of the expected physical properties of nilas, pancake, and young ice. Results from previous laboratory and field studies are also summarized. In Section III, the experimental approach used in this laboratory study is presented and focuses on the preparation of the tank facility, the instrument setup, the ice growth sequence, and the ice conditions observed. In Section IV, the measurement approach is presented and then followed in Section V by the physical characteristics of the pancake ice that was formed. In Section VI, the electromagnetic measurements and results are presented and discussed. Summary conclusions are provided Section VII.

\section{PANCAKe AND FraziL ICE PRoPerties}

\section{A. Expected Salinity Distribution}

The mechanism and rate of brine entrapment, drainage, and expulsion is dependent on whether the ice forms under quiescent or wave-agitated conditions. When conditions are quiescent, congelation ice forms and salt is entrapped in inclusions located at the planar interfaces of the boundaries of the platelets making up the lamellar substructure of the ice crystals. In the case of frazil and pancake ice, the consolidation of a crystal slurry entraps brine throughout the volume of the slurry [2]. In addition, after consolidation into pans, brine flows on and off the pan surface in association with rim building, thereby further modifying the salinity distribution. During a March study at the marginal ice zone in the East Greenland Sea, called MIZEX'87, observations were made of nilas, pancake ice, and young ice. Nilas, a congelation ice case, 2-6 cm thick, showed bulk salinities of 14.3-16.2 ppt, and a density of $0.92 \mathrm{Mgm}^{-3}$. Pans with diameters from 0.3 to 1.5 $\mathrm{m}$ and thicknesses of $5-13 \mathrm{~cm}$ were found. Rims were 1-5 $\mathrm{cm}$ above the relatively flat surface of the pan centers. Interior structure consisted of closely packed ice platelets. Salinities ranged from 9 to $12 \mathrm{ppt}$, somewhat less than that of nilas. Bulk density was also found to be the same as for the nilas at $0.92 \mathrm{Mgm}^{-3}$. Young ice, $36 \mathrm{~cm}$ thick, was found to have a bulk salinity of about $8.6 \mathrm{ppt}$ and a density of $0.92 \mathrm{Mgm}^{-3}$. These results are presented in Tucker et al. [7].

\section{B. Field Studies of Pancake Ice}

Results from the MIZEX'87 experiment also show that the radar backscatter coefficients are quite variable due to differences largely associated with pan diameter and rim height. When pan rims are small, backscatter cross sections even at the high-microwave and low-millimeter wave frequencies were only slightly above the values for nilas; however, at $9.6 \mathrm{GHz}$, the scatter was $7-10 \mathrm{~dB}$ greater. For rough pancake ice at an incidence angle of $40^{\circ}$, the backscatter enhancement was about 12 and $17 \mathrm{~dB}$ at 18 and $37 \mathrm{GHz}$, respectively. Furthermore, as is shown in Fig. 1, the GR derived for microwave backscatter $\left[\operatorname{GR}_{A M W}(37,18)\right]$ was able to differentiate open water from nilas and pancakes from first-year ice [7]. This shows that this clustering of ice forms that cannot be resolved by the passive microwave gradient ratio $\left[\operatorname{GR}_{P M W}(37,18)\right]$ have very different scattering characteristics. The passive microwave GR clearly separates the dry multiyear ice from the other categories and the pancakes from the nilas. Neither measurement was adequate for distinguishing first-year from the flooded multiyear ice, however. Similar results are obtained by using the passive microwave polarization ratio (PR) and the active microwave GR $(37,18)$. In both cases, the ability to distinguish between ice types is improved over the combination of emissivity and backscatter at a single frequency.

In SEASAT synthetic aperture radar (SAR) imagery and more recent aircraft and satellite data, it has been shown that frazil slicks appear dark and pancake ice appears bright [8]. Frazil ice has been observed to dampen the capillary and small gravity waves at the wavelengths of satellite microwave radars, thereby producing a surface that is smoother than that of the surrounding water surfaces. The rim heights on pancake ice are on the order of a few centimeters, which is sufficiently large to enhance surface scattering. An equally important enhancement is attributable to ice surfaces that are moistened with brine, thereby raising their dielectric constant and air-ice contrast [8]. In Fig. 1(b), a SAR image acquired using the European Space Agency (ESA) ERS-1 SAR is used to illustrate fields of pancake ice observed at the marginal ice zone in the Barents Sea area. Note that the pancake ice field produces backscatter levels that are similar to those of 


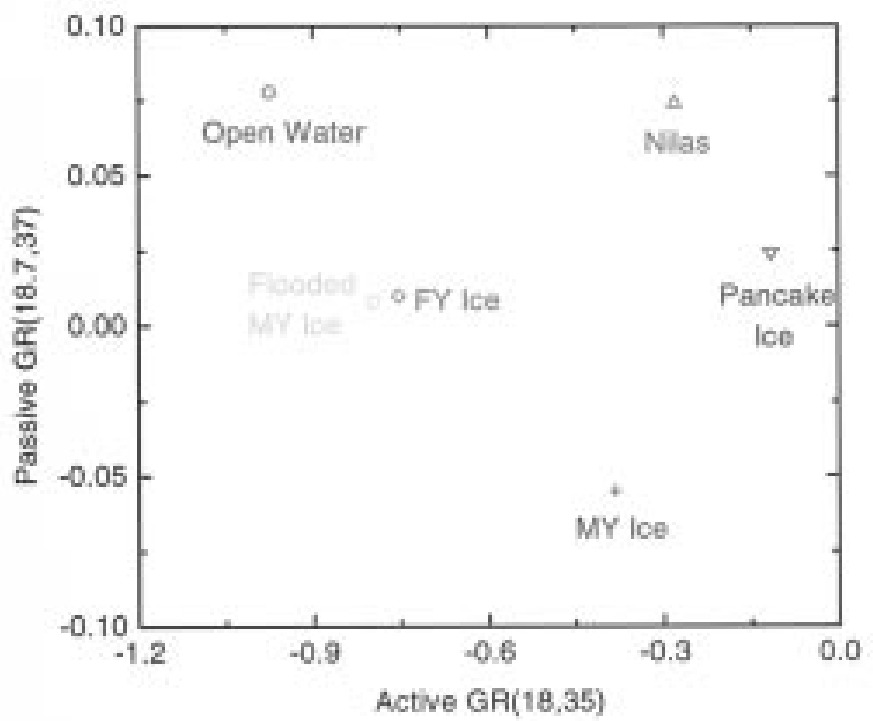

(a)

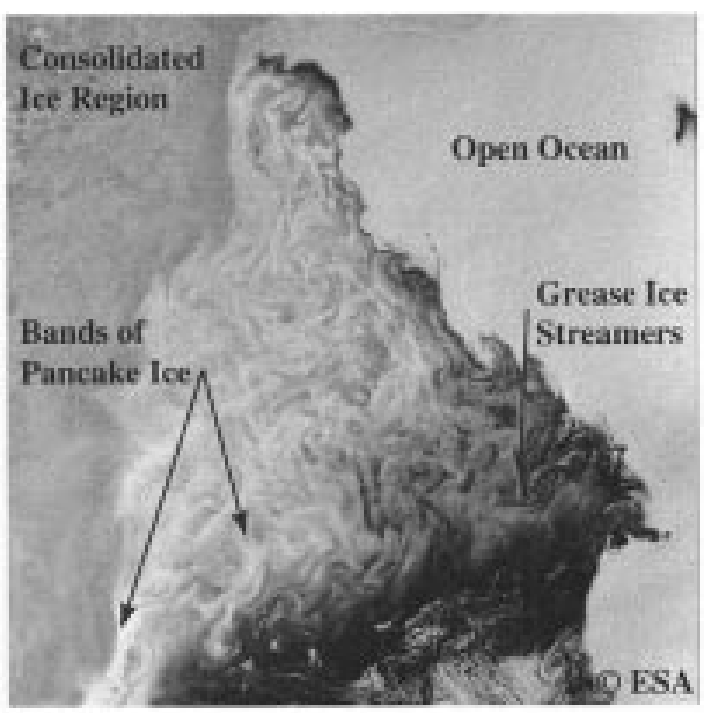

(b)

Fig. 1. Combination of active and passive microwave signatures allows for improved discrimination among open water, flooded multiyear ice, multiyear ice, first-year ice, nilas, and pancake ice (a) [7]. An example observation of the marginal ice zone on March 5, 1992, in the Barents Sea $\left(76-77^{\circ} \mathrm{N}\right)$ using the ESA ERS-1 SAR shows regions of open water, grease ice, bands of pancake ice, and consolidated ice floes (b).

the open ocean and oftentimes greater than those of regions of consolidated older and recently formed ice.

During other recent field investigations (e.g., CEAREX and LEADEX), we have studied physical processes associated with congelation ice formation and growth. This work has produced an understanding of the development of new and young ice signatures that suggests that a significant portion of the formation history is identifiable in satellite imagery [9]. Ice produced under wave-agitated conditions does not consolidate into a solid sheet until the layer of frazil, shuga, and pancake ice has sufficient mass and viscosity to damp out the wave field. Although we have some data on frazil and pancake ice from ship cruises, it has proven difficult to follow the evolution of such ice in a given location and to obtain samples because of storm conditions that are ongoing.
An in-situ study of pancake ice was made during the month of March during CEAREX'89 [2]. This allowed a comparison to be made between smooth, thick first-year ice; rough first year ice; and pancake ice. The rough first-year ice was of pancake ice origin and composed of pans of 2-3-m diameters and 4-cm-high rims. Observations of backscatter show that as roughness increases, the response at near-vertical viewing angles decreases and the middle-to-large angle backscatter increases in the case of pancake ice where the roughness and dielectric constant are high. These backscatter levels are large and on the order of those of multiyear ice and illustrate the important contribution of enhanced surface roughness and dielectric constant. As an example, observations at $9.6 \mathrm{GHz}$ for angles in the range from 10 to $70^{\circ}$ show an overall increase in the backscatter response over those observed for smooth ice of many decibels (e.g., 4-10 dB) and with values greater than those observed from the rough, thick first-year ice case [9].

\section{Previous Laboratory Experiments}

Laboratory studies conducted in the past at CRREL have largely concentrated on the evolution of water to thin ice under quiescent conditions. However, during January 1990, we succeeded in producing $16 \mathrm{~h}$ of pancake ice growth and attained an ice thickness of $7 \mathrm{~cm}$. These pancakes were very similar in shape to those that are seen in the polar oceans and with sizes well within the observed range. However, thawing conditions and the eventual failure of the wavemaker paddle due to the stress causes by an ice laden field several centimeters thick forced a premature termination of the experiment. It was shown that the pancake ice signature evolution is quite different from that of congelation ice; although for the consolidated $8-\mathrm{cm}$-thick pancake ice sheet, the emissivity spectra looked very similar to those of $8-15-\mathrm{cm}$ young ice.

Results show a surface emissivity that increased with increasing ice thickness, but emission levels never reached those of congelation ice. At a C-band frequency, the response in brightness temperature was linear with thickness, whereas with congelation ice a nonlinear behavior is found [2], [10]. This linear behavior is attributable to the mixing of ice, slush, and water [11]. A quantitative estimate of percent ice and slush was not made.

We have also noted the difficulty in quantitatively characterizing the structure and physical properties of a field of pancake ice. The emissivity of a field of pancake ice is difficult to interpret because throughout much of the growth stage, the pans of ice are smaller than the sensor spatial resolution (even when the radiometers are surface-based) and a field of pans does not represent a pure ice type. Interestingly, the net brightness temperature of a field of pancakes is, however, either a rough measure of ice thickness or the total ice mass. At the time, there was no working hypothesis as to the nature of this relationship [12]. We now hypothesize that the problem be specified as a mixture of ice and water.

\section{EXPERIMENTAL APPROACH}

This investigation was conducted at the Geophysical Research Facility (GRF) at CRREL. The GRF consists of an outdoor reinforced concrete tank filled with seawater. Its physical dimensions are $18 \times 7.5 \times 2 \mathrm{~m}$ (length, width, and 


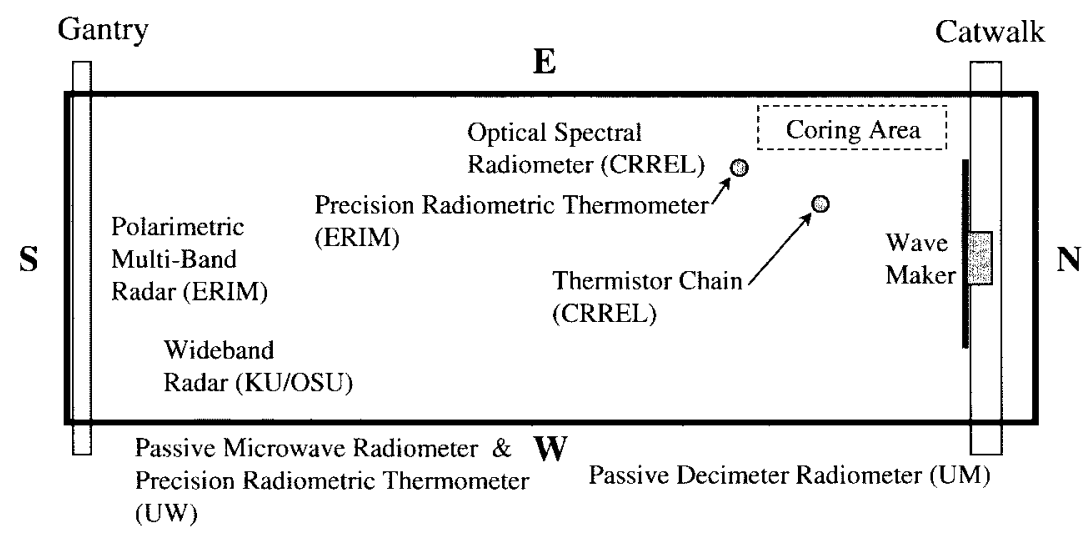

Fig. 2. Diagram of the GRF and sensor position. Sensor labels are positioned in their primary areas of operation.

TABLE I

Observations AND THEIR ChaRacteristics

\begin{tabular}{|c|c|c|c|c|c|}
\hline Observation & Symbol & $\begin{array}{l}\lambda \text {-Wavelength } \\
f \text {-Frequency }\end{array}$ & p-polarization & $\theta$-incidence angle & Instrument \\
\hline $\begin{array}{l}\text { Brightness } \\
\text { Temperature } \\
\text { Emission } \\
\end{array}$ & $\begin{array}{c}\mathrm{T}_{\mathrm{B}}(v, \mathrm{p}, \theta), \\
{ }^{\circ} \mathrm{K} \\
\mathrm{e}(v, \mathrm{p}, \theta)\end{array}$ & $\begin{array}{l}1.4,2.6,6.710,1 \\
8.7,37,90 \mathrm{GHz}\end{array}$ & $\begin{array}{l}\text { Vertical(V), } \\
\text { Horizontal(H) }\end{array}$ & $30^{\circ}$ to $60^{\circ}$ & $\begin{array}{l}\text { Microwave } \\
\text { Radiometers }\end{array}$ \\
\hline $\begin{array}{l}\text { Radar } \\
\text { Backscatter } \\
\text { Coefficient }\end{array}$ & $\begin{array}{c}\sigma^{\circ}(v, p, \theta) \\
d B\end{array}$ & $\begin{array}{c}2-16 \\
5,10,14,38 \\
\mathrm{GHz}\end{array}$ & $\begin{array}{l}\text { VV, HH, } \\
\text { VH, HV }\end{array}$ & $0^{\circ}$ to $60^{\circ}$ & $\begin{array}{l}\text { Ultra-Wideband Radar } \\
\text { Wideband Radar }\end{array}$ \\
\hline $\begin{array}{l}\text { Spectral } \\
\text { Albedo } \\
\end{array}$ & $\alpha_{\lambda}\left(\theta_{\Delta}\right)$ & $400-1000 \mathrm{~nm}$ & unpolarized & $\begin{array}{c}\text { nadir \& zenith viewing, } \\
\theta_{\mathrm{a}}=\text { solar zenith angle }\end{array}$ & $\begin{array}{l}\text { Spectro- } \\
\text { photometer }\end{array}$ \\
\hline $\begin{array}{c}\text { Thermal IR } \\
\text { Emissivity }\end{array}$ & $\mathrm{e}(\theta)$ & $8-14 \mu \mathrm{m}$ & unpolarized & $0^{\circ}, 30^{\circ}-60^{\circ}$ & $\begin{array}{c}\text { Infrared } \\
\text { Radiometer }\end{array}$ \\
\hline $\begin{array}{l}\text { Temperature } \\
\text { Air } \\
\text { Ice Surface } \\
\text { Ice Intcrior }\end{array}$ & $\begin{array}{l}\mathrm{Ta},{ }^{\circ} \mathrm{C} \\
\mathrm{Ti}^{\circ}{ }^{\circ} \mathrm{C} \\
\mathrm{Ti}^{\circ}{ }^{\circ} \mathrm{C}\end{array}$ & $\begin{array}{l}-- \\
-- \\
-- \\
\end{array}$ & $\begin{array}{l}-- \\
-- \\
--\end{array}$ & $\begin{array}{l}- \\
-- \\
-\end{array}$ & $\begin{array}{c}\text { Me1 Station }(10 \mathrm{~m}) \\
\text { Thermistors } \\
\text { Thermistors }\end{array}$ \\
\hline $\begin{array}{l}\text { Salinity } \\
\text { Ice } \\
\text { Profile }\end{array}$ & $\begin{array}{l}\text { S, ppt } \\
\text { S, ppt }\end{array}$ & $\begin{array}{c}1 \mathrm{~mm} @ \\
0-5 \mathrm{~mm} \\
2 \mathrm{~cm} \text { segments }\end{array}$ & $\begin{array}{l}-- \\
--\end{array}$ & -- & $\begin{array}{l}\text { Refractometer } \\
\text { Salinometer }\end{array}$ \\
\hline Roughness & $\sigma \mathrm{cm}$ & $\ldots$ & -- & - & $\begin{array}{c}\text { Carpenter's Comb } \\
\text { vertical Thick Sections }\end{array}$ \\
\hline
\end{tabular}

depth). Facility support included water filtering, a movable roof structure incorporating cooling ducts, and a heavy-duty, refrigeration system. A 6-m-high movable gantry was used to support sensors above the water or ice surface. A catwalk that extended across the tank allowed samples to be retrieved when the ice was thin, or facilitated the positioning of nearsurface instrumentation. The gantry and catwalk moved on rails that ran the entire length of the tank. A schematic of the GRF, including sensors, ice sampling, gantry, and wavemaker locations, is shown in Fig. 2.

\section{A. Sea Water Preparation}

The GRF test tank was filled with saline water that was prepared by mixing the constituent components of seawater. Sodium chloride and six secondary or trace components were added to the sea water mixture to replicate the properties of standard polar ocean water. The target salinity of the body of saline water was 29-31 ppt for this investigation. The saline body was then cooled to near its freezing point, thereby allowing ice to rapidly form once the experiment was initiated.

\section{B. Wavemaker}

A paddle-type wavemaker was used to produce the tank wave field. The wavemaker was fastened to the movable gantry at the most northern tank position with the paddle approximately perpendicular to the water surface. An 8-horsepower motor with speed control drove the wavemaker. A wave height of $\pm 0.3 \mathrm{~m}$ was produced when the tank was free of ice and when covered by several centimeters of frazil ice crystals. The electromagnetic observations were made along the entire length of the tank. The opposite end of the tank had a sloping face, which acted to reduce the reflection of waves back to the wavemaker.

\section{Electromagnetic Measurements and Instrumentation}

A diverse set of instruments was used to measure the electromagnetic properties of the evolving sea ice scene. The set included passive microwave radiometers, microwave radars, optical spectrophotometers, and infrared precision radiometers. Observations were multiplexed so that issues of cross talk were mitigated. Instruments were positioned at different locations about the tank, based on instrument size and operational constraints. One set of microwave radar and passive microwave instruments was able to be translated along the ice sheet. Instrument locations are shown in the tank site diagram, Fig. 2. Instrument parameters and data acquired are provided in Table I. Views of the GRF from the north and 


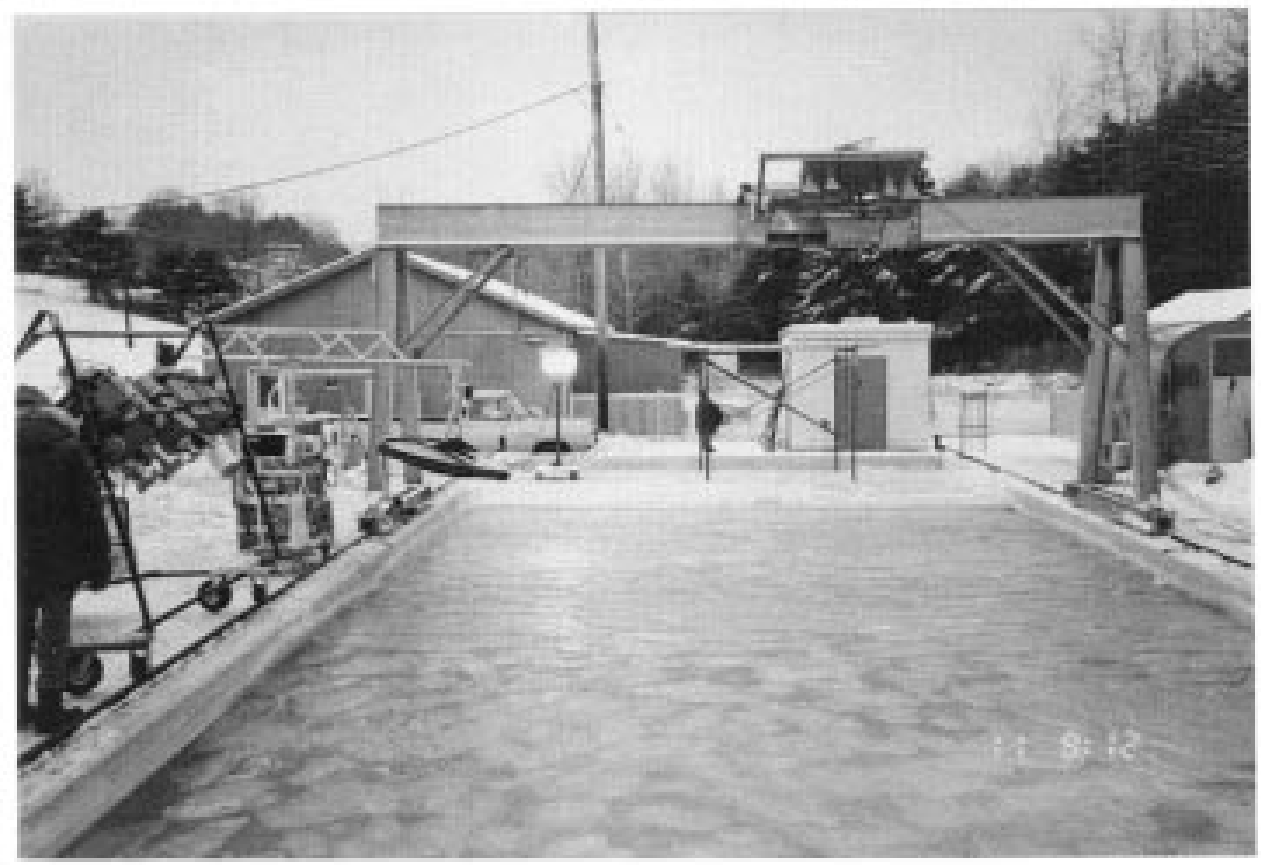

(a)

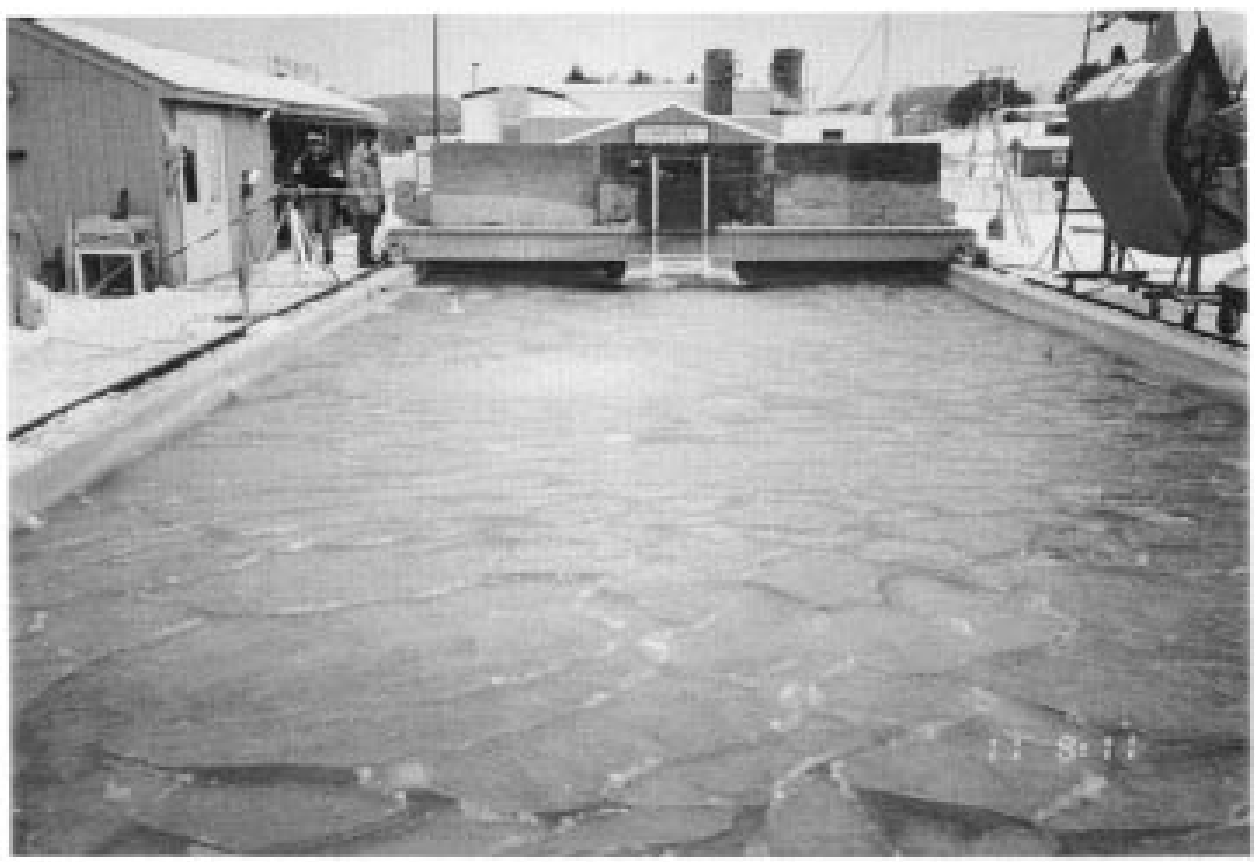

(b)

Fig. 3. Views of the GRF showing (a) the polarimetric multiband radar mounted on the movable gantry and passive microwave radiometer suite (looking south) and in (b) the wavemaker, a passive decimeter radiometer (right side), Precision Radiometric Thermometer (left side to the far tank end), and the movable roof (center).

the south are shown in Fig. 3. The pancake ice field shown is about 15 -h old.

\section{Ice Growth Sequence}

Observations began with calm, ice-free seawater and an ambient air temperature of $-14^{\circ} \mathrm{C}$. For a major portion of the ice formation process (about $85 \%$ ), the ambient temperature remained very cold (at or below $-15^{\circ} \mathrm{C}$ ). Pertinent environmental conditions during ice formation are shown in Fig. 4.
Calm, ice-free seawater served as a reference point from which to compare all other observations. Frazil ice was nucleated by the use of two submersible pumps. After stopping the pump action, a very thin, 5-mm-thick layer of semiconsolidated frazil ice formed. Wave action was then initiated and thin frazil ice slurry was produced. Within about $2 \mathrm{~h}$, a prominent layer of frazil ice had formed. The impinging waves produced by the wavemaker propelled the floating ice crystals toward the opposite end of the tank. Grease ice was apparent $3 \mathrm{~h}$ after the 


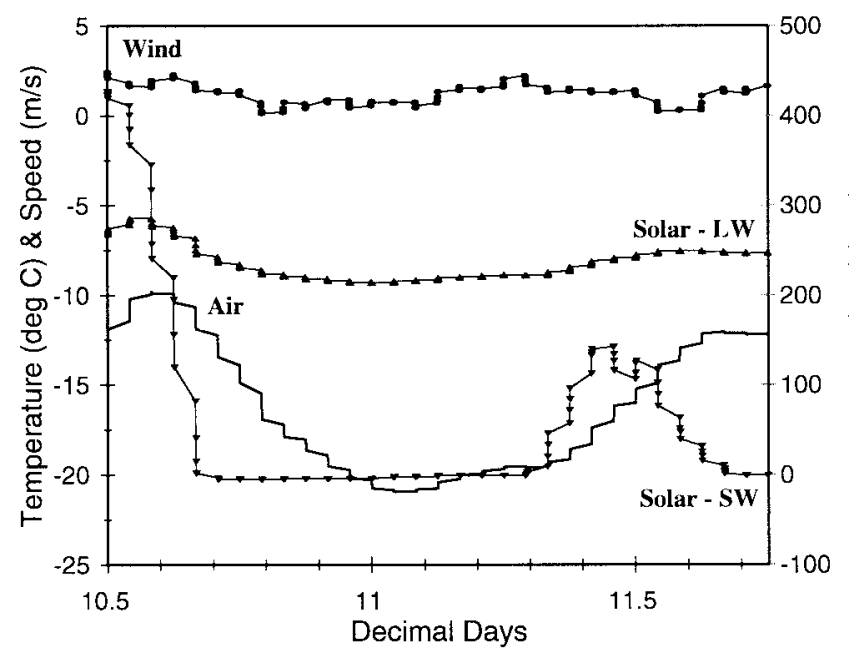

(a)

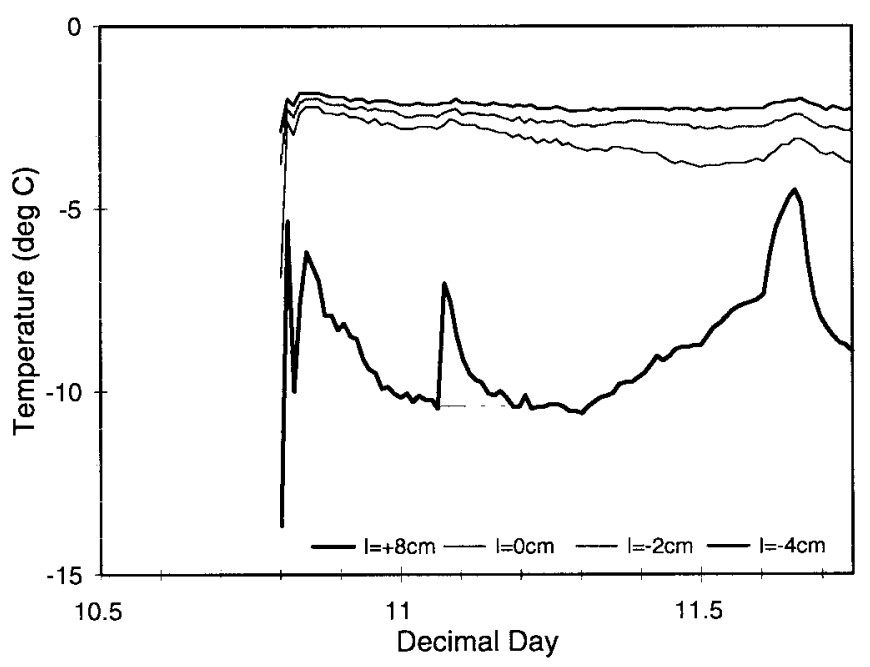

(b)

Fig. 4. (a) Data collected from a nearby meteorological station (within $0.3 \mathrm{~km}$ ) are shown for the time period during which open water was transformed into pancake ice. (b) The air and ice sheet profile temperatures are shown as a function of decimal time in days. The temperature locations within and above the ice are at $+8,0,-2$, and $-4 \mathrm{~cm}$. The elevation of the near-surface temperature at 11.1 days would have been caused by the wetting of the thermistor. A high wave or the repositioning of the probe would have caused this to occur. A line is included to indicate the expected response.

TABLE II

Summary of Ice Formation and EnVIronmental Conditions

\begin{tabular}{|c|c|c|c|c|c|}
\hline $\begin{array}{l}\text { Dec } \\
\text { Day }\end{array}$ & $\begin{array}{c}\text { Growth } \\
\text {-hours- }\end{array}$ & ID & $\begin{array}{r}h_{\text {ice }} \\
-\mathrm{cm}-\end{array}$ & Comment & $\begin{array}{c}\text { Temperature }\left({ }^{\circ} \mathrm{C}\right) \\
\text { Salinity (ppt) }\end{array}$ \\
\hline 10.7083 & 0.0 & OW & 0 & open water, experiment starts & $S=30$ \\
\hline 10.7674 & 1.4 & OW & 0 & open water, calm, no wind & \\
\hline 10.8403 & 3.2 & WAV & 0 & wave action started, wave period $1 \mathrm{hz}$ & \\
\hline 10.8505 & 3.4 & $\mathrm{G}$ & grease & light grease ice has formed & \\
\hline 10.8542 & 3.5 & $\mathrm{G}$ & grease & frazil starting to clump, silver dollars forming & \\
\hline 10.9236 & 5.2 & G & grease & grease ice thickening & $\mathrm{T}_{\mathrm{a}}=-28, \mathrm{~T}_{\mathrm{i}}=-1.7, \mathrm{~S}=29$ \\
\hline 10.9653 & 6.2 & S1 & slush & grease ice getting thicker, no pans & $T_{a}=-22, T_{i}=-1.7$ \\
\hline 11.0486 & 8.2 & S2 & slush & few small pans, $11 \mathrm{~cm}$ and round & $T_{i}=-2$ \\
\hline 11.0750 & 8.8 & S3 & slush & few small pans & \\
\hline 11.1007 & 9.4 & PS & 2 & few small pans & $\mathrm{T}_{\mathrm{i}}=-2.2, \mathrm{~T}_{\mathrm{a}}=-19$ \\
\hline 11.1354 & 10.3 & PS & 1.5 & pancake field beginning to form & $T_{a}=-20 T_{i}=-2.2$ \\
\hline 11.1736 & 11.2 & PS & 1.5 & $1 \mathrm{~cm}$ of firm ice, $0.5 \mathrm{~cm}$ slush bottom, rims are raised & $T_{a}=-20$ \\
\hline 11.2917 & 14.0 & PL & 3 & large pans forming & \\
\hline 11.3333 & 15.0 & PL & 3 & ice is congealing & \\
\hline 11.3542 & 15.5 & PL & 3 & waves now attenuated & \\
\hline 11.4167 & 17.0 & PLS & 6 & surface has frozen & $\mathrm{T}_{\mathrm{a}}=-15.1$ \\
\hline 11.4750 & 18.4 & PL3 & 6 & ice sheet consolidating, and thickening & $\mathrm{T}_{\mathrm{a}}=-15.1$ \\
\hline 11.5250 & 19.6 & PL4 & 6 & ice sheet consolidating, and thickening & $\mathrm{T}_{\mathrm{a}}=-15.1$ \\
\hline 23.8542 & 316 & IS & 12 & sheet consolidated and thickened & $\mathrm{T}_{\mathrm{s}}=-2.2, \mathrm{~T}_{\mathrm{i}}=-4$ \\
\hline 24.8472 & 340 & IS & 12 & ice sheet metamorphosing & \\
\hline 25.5417 & 353 & IS & 12 & ice sheet metamorphosing & $T_{a}=-1, T_{1}=-2.3$ \\
\hline 25.8472 & 363 & IS & 12 & ice sheet metamorphosing & $\mathrm{T}_{\mathrm{a}}=-6, \mathrm{~T}_{\mathrm{i}}=-5$ \\
\hline
\end{tabular}

start of the experiment, small silver dollar-sized clumps of ice crystals at $3.5 \mathrm{~h}$ and large $10-30-\mathrm{cm}$ diameter pans at $14 \mathrm{~h}$. When the ice attained a thickness of $3 \mathrm{~cm}$, the wavemaker was no longer able to produce the energy required to modulate the field of pans and prevent the consolidation of the pans into an ice sheet. Prominent formation event information, hours of growth, ice thickness, and ice surface temperature are provided in Table II. A mosaic of photos taken at different times during pan formation is shown in Fig. 5.

\section{E. Environmental Parameters and Ice Characterization}

Ice thickness was measured by removing samples from the pool. Surface air temperature, sensible heat flux, and radiation fluxes were measured using a weather station located several tens of meters from the GRF. A thermistor chain frozen vertically into the ice was also used to measure temperatures about the air-water interface, into the ice and water column, and the layer of air immediately above the air-ice interface. Throughout the growth process, vertical profile measurements of temperature, density, salinity, and structural characteristics of the ice were made. Salinities of melted samples were made with a Beckman Solubridge with a measurement precision estimated at $\pm 0.2 \mathrm{ppt}$. Both vertical and horizontal thin sections of several pans were prepared with the aid of a microtone. Sections were then photographed between cross polarizers to document the crystalline structure of the ice in the 


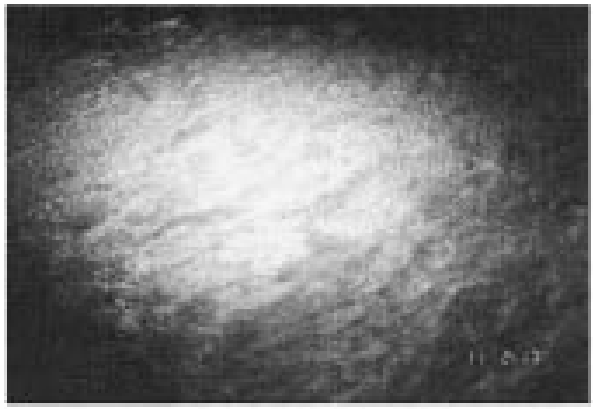

After 8 hours

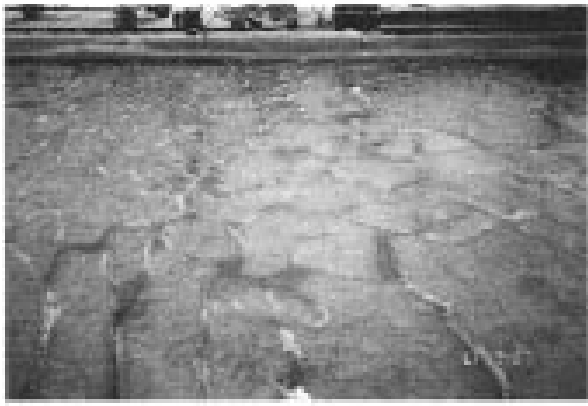

After 15 hours

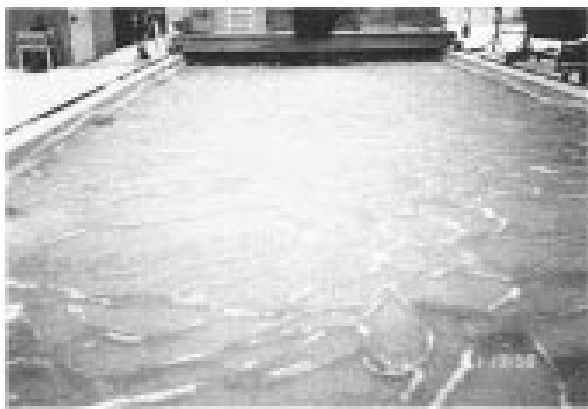

After 20 hours

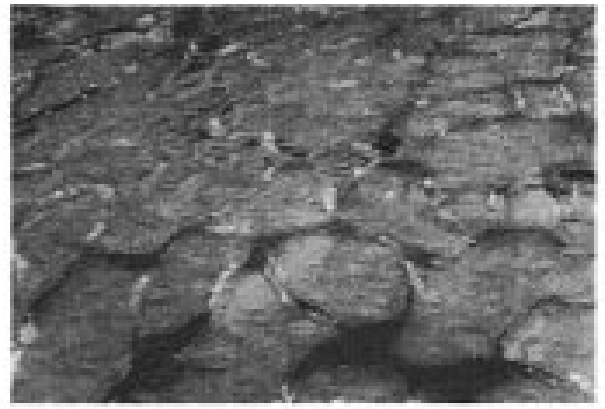

After 14 hours

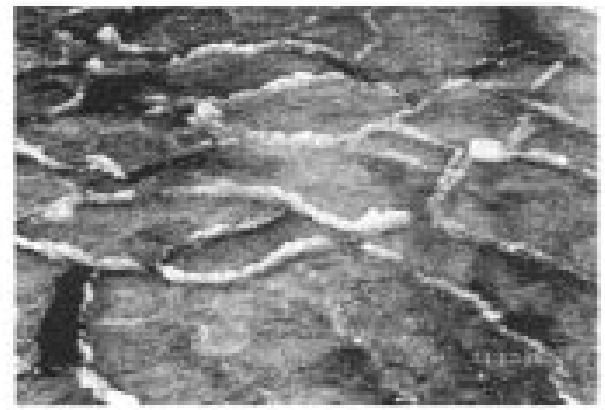

After 17 hours

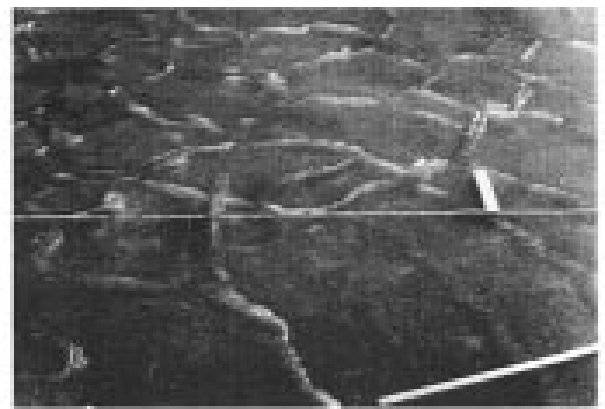

After 380 hours

Fig. 5. This collection of photos shows the change in ice conditions from the formation of frazil ice and pans of ice and then to the consolidation of the pans into an ice sheet. Conditions are shown as a function of hours of growth.

pans and to retrieve brine inclusion size distribution. Surface roughness was measured using a carpenter comb-like device and vertical thin sections retrieved from ice pans.

\section{F. Description of the Spatial Distribution of Pancake Ice Pans in the Tank}

The size of the ice pans was found to be dependent on the distance from the wavemaker. The largest pans are located at the tank end opposite the wavemaker. Variable pan size is attributable to the wave-attenuation effect of an ice layer composed of frazil, grease, shuga, and pancake ice. The ice layer acts as a lowpass filter. The thicker and more consolidated the ice layer, the lower the wave frequency that may propagate. This field of pans of varying size provided a critical opportunity to associate electromagnetic signature with pan size and rim height. Instrument scans in the along-track dimension of the tank were performed to spatially average the signals for present purposes.

\section{MEASUREMENT APPROACH}

This investigation was conducted during the month of January 1995 when ambient conditions are historically very cold and uninterrupted by thaw and rain. Observations were first made of calm open water, a reference scene also used in the previous investigations. Wave action was applied and continued for about $14 \mathrm{~h}$, by which time pans $3 \mathrm{~cm}$ thick had formed. The electromagnetic and physical property observations were made continuously during the first 24-h period during which the pans formed and consolidated into an ice sheet. For most of the ice formation process, the ambient air temperature was about $-20{ }^{\circ} \mathrm{C}$. The ice sheet was then revisited 12 days later to examine modifications associated 


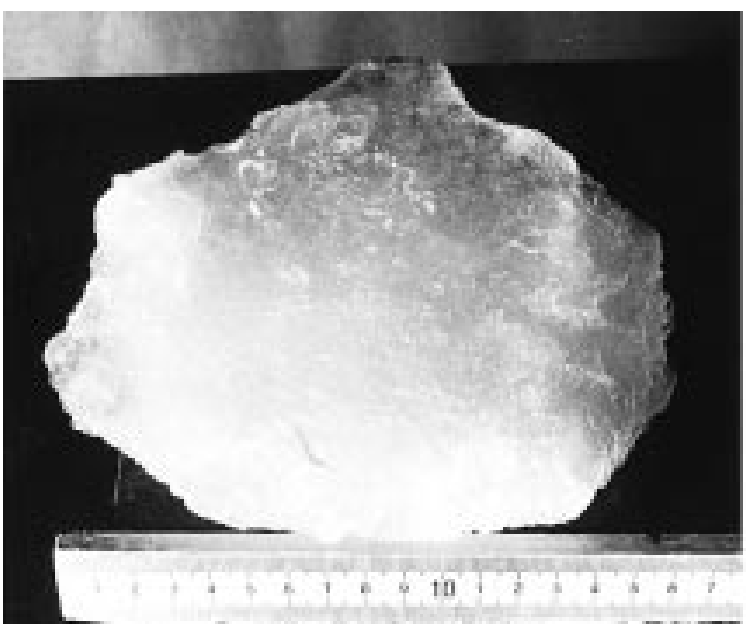

(a)

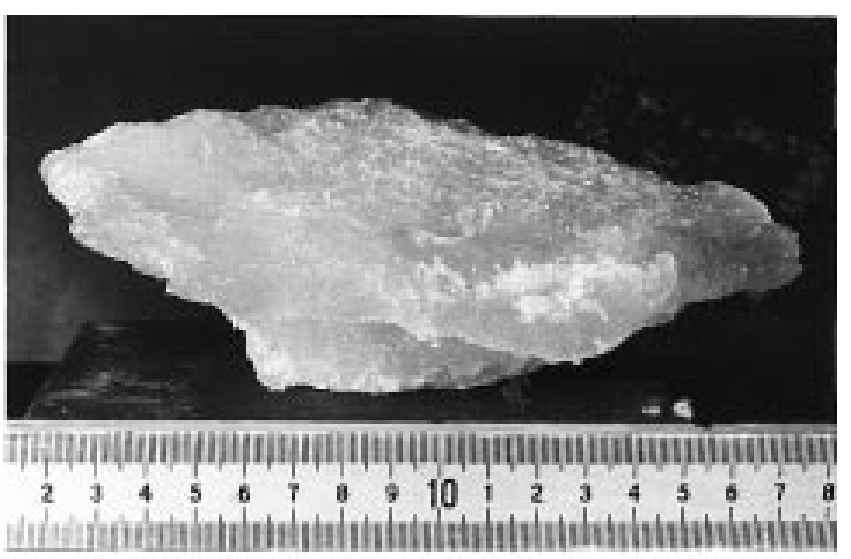

(b)

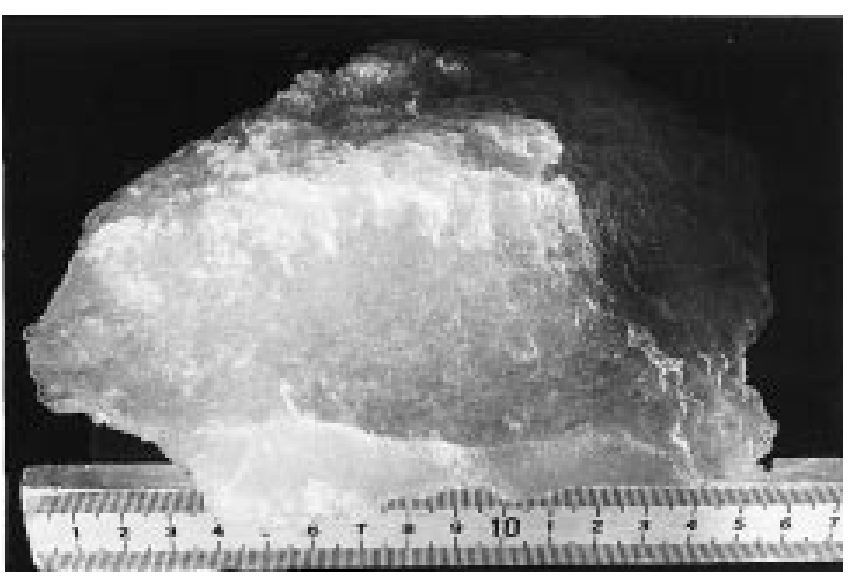

(c)

Fig. 6. External characteristics of a pan retrieved after $14 \mathrm{~h}$ of ice growth: (a) top view of the pan, (b) side view, and (c) bottom view of pancake 1 .

with the normal aging processes that includes ice accretion, desalination, and surface metamorphism. Physical property measurements were also made at intervals throughout the ice formation process. Observations were made of the vertical profiles properties of the ice features (e.g., temperature, salinity, brine volume, crystal size, brine pocket size, and air bubble size), the vertical height statistics of the air-ice interface, and the ambient environmental conditions recorded (e.g., wind speed, wind direction, air temperature, long wave radiation, shortwave radiation, and humidity).

\section{Physical Characteristics of Pancake ICE}

Representative pans were retrieved from the ice sheet for characterization. Top, side, and bottom views of one such pan removed $14 \mathrm{~h}$ into the experiment period is shown in Fig. 6. The major and minor axes of the pan are $16 \times 13 \mathrm{~cm}$. Viewing from the side, the pan bottom is convex in shape [see Fig. 6(b)]. Slush ice, which was pushed on the edge of this pan, could be cleared-showing an upper surface that is concave in shape. The pan ice is composed of randomly oriented crystals and shows a high concentration of brine. Crystal structures through the center section of two pans, together with their interior salinity distributions, are shown in Fig. 7.

\section{A. Surface Roughness Measurements}

The roughness of the air-ice interface for 1) recently formed ice pans and 2) pans a few days old were measured. Measurements were made using two techniques. One technique required the removal of a pan of ice, processing to obtain a series of vertical thin sections, and then photographs of the air-ice interface [9]. A second method used a "carpenters comb-like tool." This tool has closely spaced thin wire elements that conform to the roughness of the surface. Results of the spatial statistics derived from these measurements are provided in Table III. Statistics obtained from several pans include the vertical height rms roughness and correlation lengths for a full pan and the flat area of a pan.

The roughness of a pan center is about twice that of ice grown under quiescent conditions. This increase in roughness is associated with the congealing of clumps of ice crystals in the case of pancake ice versus a much less-dense suspension of small crystals in the case of congelation ice. For pans that have recently formed, the distribution of rim height and width about a pan is variable. Rim heights range from 0 to $1.8 \mathrm{~cm}$, rim widths from 0.8 to $2.9 \mathrm{~cm}$, and rim extent about the circumference of a pan from 0.9 to $10 \mathrm{~cm}$. Rms heights were difficult to measure, but fall within the range from 0.052 


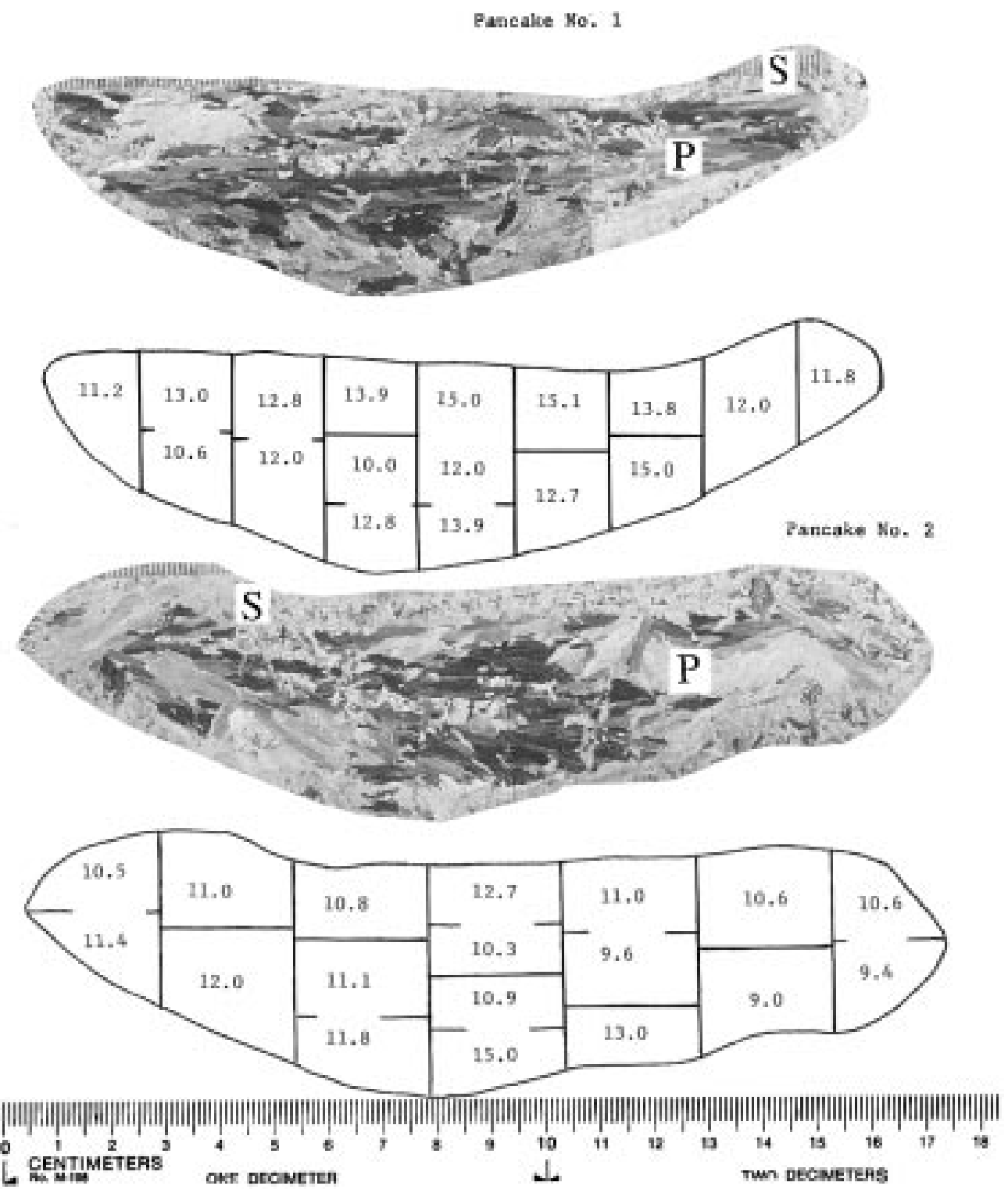

Fig. 7. Crystal structure in vertical cross section and interior salinity distribution (ppt) are shown for two pans removed after about $14 \mathrm{~h}$ of ice growth. The sequence of ice textures from top to bottom of each pancake is slush ice $(\mathrm{S})$ underlain by frazil platelets $(\mathrm{P})$.

TABLE III

Statistics for Roughness of Recently Formed Pans About $30 \mathrm{~cm}$ in Diameter

\begin{tabular}{l|c}
\hline \multicolumn{1}{c|}{ Pan Feature } & Value \\
\hline $\begin{array}{l}\text { Vertical Roughness RMS }(\mathrm{cm}) \\
\text { Pan Center }\end{array}$ & $\begin{array}{r}\text { Typical }=0.092, \text { Range }=0.052 \text { to } 0.506 \\
\text { Range }=0.018 \text { to } 0.506\end{array}$ \\
Full Pan & Typical $=1.36$, Range $=0.740$ to 1.590 \\
Correlation Length $(\mathrm{cm})$ & Range $=0.74$ to 2.765 \\
Pan Center & 0 to 1.8 \\
Full Pan & 0.8 to 2.9 \\
Rim & 0.9 to 10 \\
Height $(\mathrm{cm})$ & \\
Width $(\mathrm{cm})$ & \\
Duration of Major Rim Feature $(\mathrm{cm})$ & \\
\hline
\end{tabular}

to 0.506 . For the case of an ice sheet several days in age and which has no snow cover, peak-to-peak rim height range from 0.04 to $1.51 \mathrm{~cm}$ with rms height ranging from 0.009 to $0.506 \mathrm{~cm}$. The height values vary from pan-to-pan and with distance from the wavemaker (see Table IV). Correlation lengths range from 0.74 to $3.73 \mathrm{~cm}$. The distribution of pan 
TABLE IV

Statistics of Pancake Ice Surface for a Metamorphosed Ice Sheet

\begin{tabular}{c|c|c|c|c|c|c}
\hline $\begin{array}{c}\text { Position } \\
(\mathbf{m})\end{array}$ & $\begin{array}{c}\text { RMS Height } \\
(\mathbf{c m})\end{array}$ & $\begin{array}{c}\text { Slope } \\
(\mathbf{d e g})\end{array}$ & $\begin{array}{c}\text { Corr. Length } \\
(\mathbf{c m})\end{array}$ & $\begin{array}{c}\text { Pan Length } \\
(\mathbf{c m})\end{array}$ & $\begin{array}{c}\text { Rim Height } \\
(\mathbf{c m})\end{array}$ & $\begin{array}{c}\text { Rim Duration } \\
(\mathbf{c m})\end{array}$ \\
\hline 1.8 & 0.062 & 0.082 & 1.950 & 22.2 & 0.64 & 6.35 \\
\hline 3.0 & 0.056 & 0.092 & 1.184 & $>25$ & 1.11 & 5.87 \\
\hline 3.7 & 0.009 & 0.033 & 2.059 & $>25$ & 0.40 & 0.00 \\
\hline 4.9 & 0.198 & 0.147 & 2.328 & $>25$ & 1.39 & 9.53 \\
\hline 6.1 & 0.141 & 0.171 & 1.574 & 14.9 & 1.35 & 7.62 \\
\hline 6.7 & 0.210 & 0.056 & 3.342 & 21.6 & 1.31 & 12.07 \\
\hline 7.9 & 0.156 & 0.092 & 3.694 & $>25$ & 1.35 & 12.07 \\
\hline 8.5 & 0.175 & 0.064 & 3.733 & 26.7 & 1.51 & 11.43 \\
\hline 9.1 & 0.099 & 0.077 & 2.087 & $>15$ & 1.19 & 5.08 \\
\hline 9.1 & 0.506 & 0.340 & 2.765 & 15.3 & 1.11 & 5.00 \\
\hline 9.1 & 0.018 & 0.239 & 0.740 & 17.1 & 0.79 & 4.50 \\
\hline 9.1 & 0.097 & 0.259 & 0.847 & 15.3 & -- & -- \\
\hline 9.1 & 0.052 & 0.336 & 1.590 & 17.1 & -- & -- \\
\hline
\end{tabular}

and rims sizes at a growth time of $14 \mathrm{~h}$ is illustrated in a set of photographs shown in Fig. 8. The taller the rim, the whiter the appearance, due to the drainage of the brine from the pile of granular ice crystals forming the rim.

In association with the aging of an ice sheet, a metamorphism of the air-ice interface occurs, surface roughness elements become more rounded, and there is some reduction in the overall height extent. In this study case, the freeze-thaw cycling conducted under the roof of the tank contributed to the metamorphism. In the Arctic environment and during spring, there is phase-change cycling associated with changing energy balance and solar conditions.

\section{B. Pan Size Survey}

Once the ice sheet has consolidated, the record of pan size and rim location is frozen in time. Pan size is determined from a mosaic of photographs taken along the entire length of the tank. A survey tape was positioned at the center of the alongtrack dimension of the tank to provide position and length scale information. Three distinct pan regions are observed. In Region $\mathrm{A}$, the first third of the tank starting at the south end, the pans have major-minor axes of about $110 \times 50 \mathrm{~cm}$, in Region B, the next sixth of the tank, the pans are about $45 \times 30 \mathrm{~cm}$, and in Region C, the last half of the tank, the pans are about $30 \times 15 \mathrm{~cm}$. The floe size profile is shown in Fig. 9.

\section{Salinity Profiles}

Various observations of the distribution of brine during the formation and consolidation of the pans were made. These included ice surface scraping, measurement of the spatial distribution of salinity within the vertical plane of an ice pan, and a representative one-dimensional (1-D) description of the salinity profile of an ice sheet formed from pans. A summary of the temporal history of surface and bulk salinity is provided in Fig. 10. During the 14-day study, there is a continual reduction in bulk salinity with the transformation and aging of the ice forms [see Fig. 10(b)]. For example, the ice sheet consisting of pans increased in ice thickness from 4 to $12 \mathrm{~cm}$ and desalinated from 13 ppt to about 5 ppt in the bulk [see Fig. 10(a), (b)].

The determination of the distribution of salinity within a pan is based on machining contiguous samples from a 1-cm-thick slice taken from the center of the pan and then measuring their salinity. The two pans analyzed in this manner show salinities that range from 9 to $15 \mathrm{ppt}$ (see Fig. 7). The salinity of the surface layer near the pan center is elevated slightly by up to 2 ppt (relative to the off-center pan areas). The pan center is often visibly wet (See Fig. 8). Slush accumulation on the pan edges releases brine that drains to the pan center (See Fig. 7). The redistribution of brine happens rapidly, even in the case of surface salinity of the ice pans. In Fig. 10(c), the salinity of the first millimeter of a pan center decreases from its initial value of 43 to $17 \mathrm{ppt}$ over a 4-h period. Rim and internal values decrease by $16 \%$ during this same period.

Knowledge of the salinity profile properties of ice is important because its relationship to the effective dielectric constant presented to the microwave sensors. Emission is related proportionally to the magnitude of the reflection coefficient and the backscatter to the square of the reflection coefficient. Since the magnitude of the reflection coefficient follows a ratio that includes the square root of the dielectric constant in both the numerator and denominator, a change in salinity most often results in a change in electrical and electromagnetic properties.

\section{Pan Vertical Thin Sections}

The crystalline characteristics of pancake ice, as revealed in thin section photographs of two pans, are shown in Fig. 7. Platelet crystal orientations in the interior of each pan do not appear totally random; many are elongated, to some degree, about the horizontal dimension. Platy crystals range in size from a few millimeters to $2 \mathrm{~cm}$. Slush ice crystals on tope of the pans are much smaller, of the order of 1-2 $\mathrm{mm}$.

Planar views of ice sheets about $12 \mathrm{~cm}$ thick are shown in Fig. 11. The pair of vertical thin sections are from a pancake ice sheet about 380-h old (a) and for an ice sheet formed under quiescent conditions (b). The difference in the 

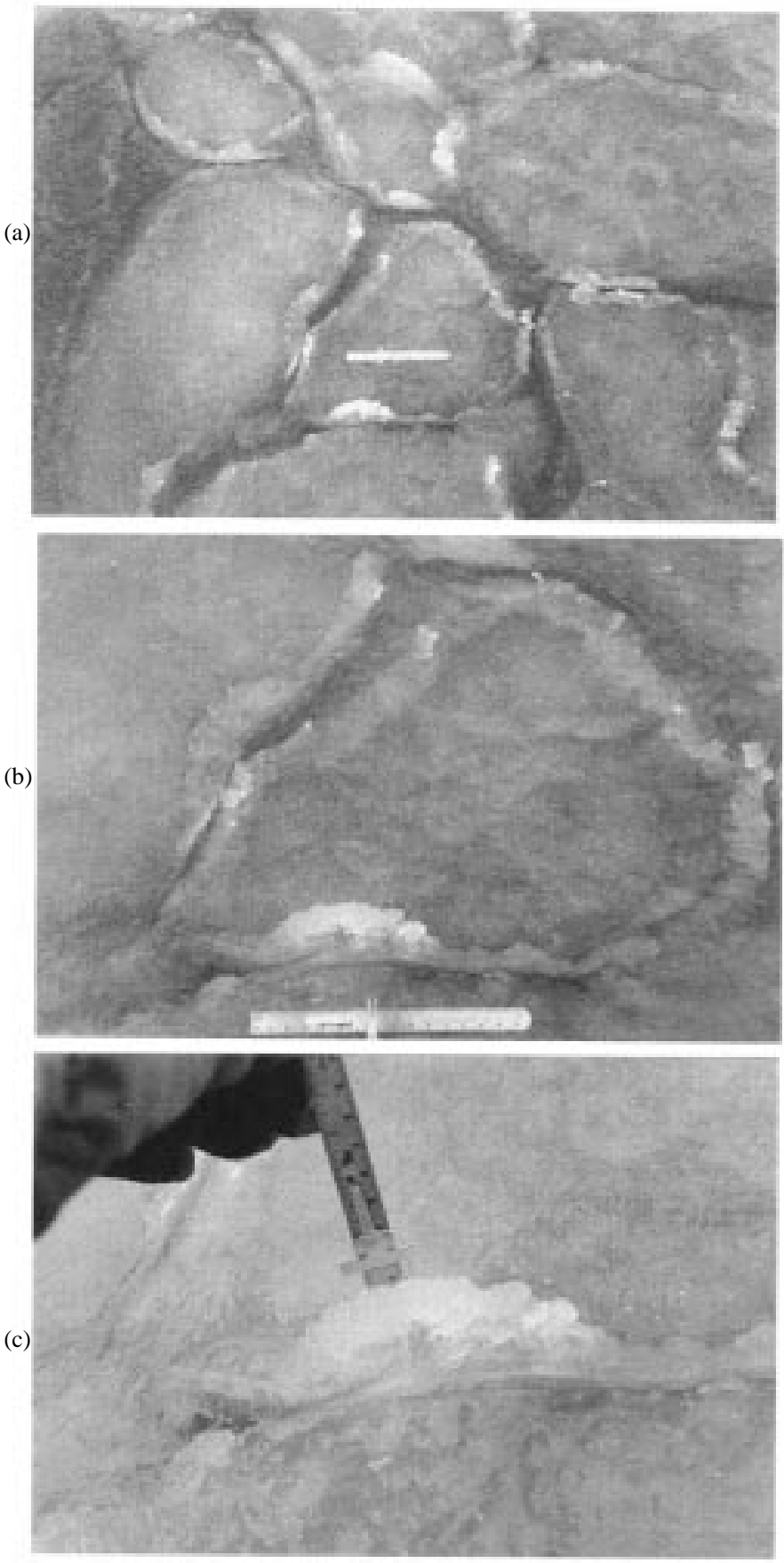

Fig. 8. Patch of pans $75 \times 110 \mathrm{~cm}$ is viewed about midday on January 11 (a). About $14 \mathrm{~h}$ of growth has occurred. This close-up shows the placement of rims about the boundary of a pan (b). Rims of slush are piled on the pan edge and range in height from 1 to $3 \mathrm{~cm}(\mathrm{c})$. The surface of a pan at this stage is moderately rough in the flat areas due to the packing of clumps of frazil ice crystals. The surface is also moistened with brine. The steel rule is $15.5 \mathrm{~cm}$ in length (photos by R. Onstott).

crystalline structure of these two ice forms is dramatic [see Fig. 11(b)]. In the case of congelation ice, the granular ice layer found in the uppermost portion of the ice layer is only a few millimeters thick. The transition to columnar ice is very rapid, with the a-plane of the crystals oriented in direction of the heat flow (e.g., vertical). The crystals are large, extending several centimeters. In the pancake case [see Fig. 11(a)], the

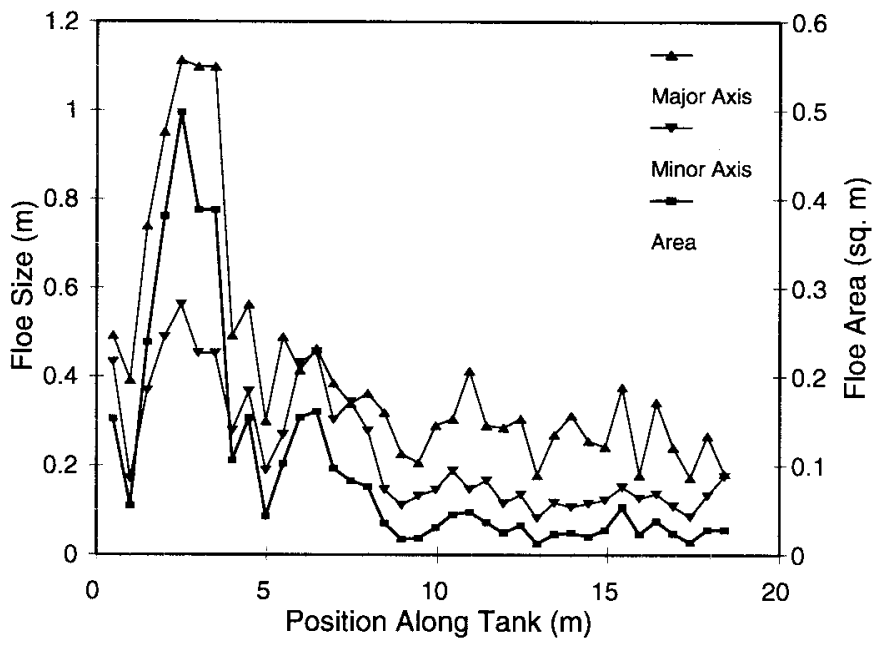

Fig. 9. Average pancake size is shown as a function of position along the length of the tank. The origin of the $\mathrm{x}$-axis is the south end of the tank.

initial frazil ice layer is difficult to distinguish, but it is about $1 \mathrm{~cm}$ in extent. Below that, the ice crystals orient more toward the vertical and the crystal sizes are small, about $0.5-1 \mathrm{~cm}$.

\section{Discussion of Electromagnetic Results}

During freezing conditions with waves present, clumps of ice crystals and pans may form. Constant wave agitation also maintains gaps composed of water or slush between these pans and clumps. During this study, the gaps were predominately filled with slush. To characterize the composite signature observed by a sensor, we use a linear mixture model to account for the fractional areas occupied by ice crystal clumps versus seawater, or ice pans versus slush. The composite signature may then be expressed as

$$
S_{c}=f_{1} S_{1}+\left(1-f_{1}\right) S_{2}
$$

where $S_{c}$ is the composite signature, $S_{1}$ is the signature of water or slush, $S_{2}$ is the signature of ice clumps or pans, $f_{1}$ is the fraction of category 1 , and $\left(1-f_{1}\right)$ is the fraction of category 2. The signature may be brightness temperature, radar scattering coefficient, spectral albedo, transmissivity, or a variety of other electromagnetic signatures.

\section{A. Optical Response}

Spectral albedos $[\alpha(\lambda)]$ and reflectance $[\rho(\lambda)]$ are calculated from the ratio of the measured reflected $\left[E_{u}(\lambda, \pi)\right]$ and incident $\left[E_{d}(\lambda, \pi)\right]$ spectral irradiance

$$
\alpha(\lambda)=\frac{E_{u}(\lambda, \pi)}{E_{d}(\lambda, \pi)} \quad \text { and } \quad \rho(\lambda)=\frac{E_{u}(\lambda, \Psi)}{E_{d}(\lambda, \Psi)}
$$

where albedo is integrated over the hemisphere above the ice sheet and reflectance is for a narrow field of view given by $\psi$. Albedos were measured using a cosine collector, which averaged over an area included many pancakes, while reflectances were measured using a narrow field-of-view lens. The reflectance measurements were confined to the interiors of the ice pans and do not include contributions from areas between the pans. 


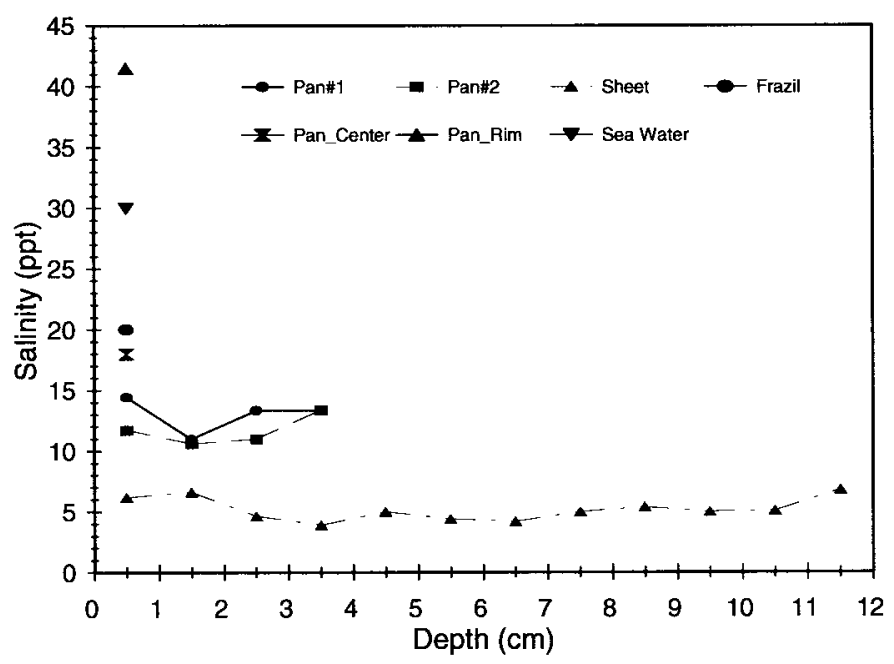

(a)

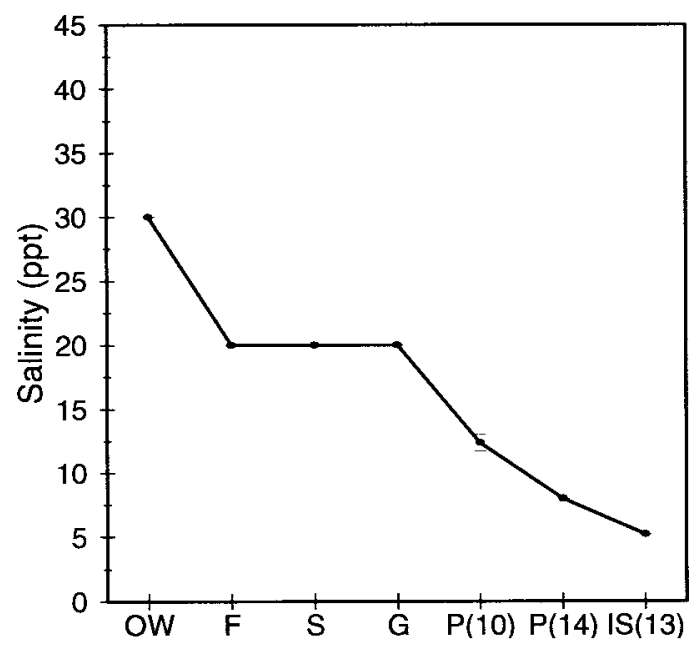

(b)

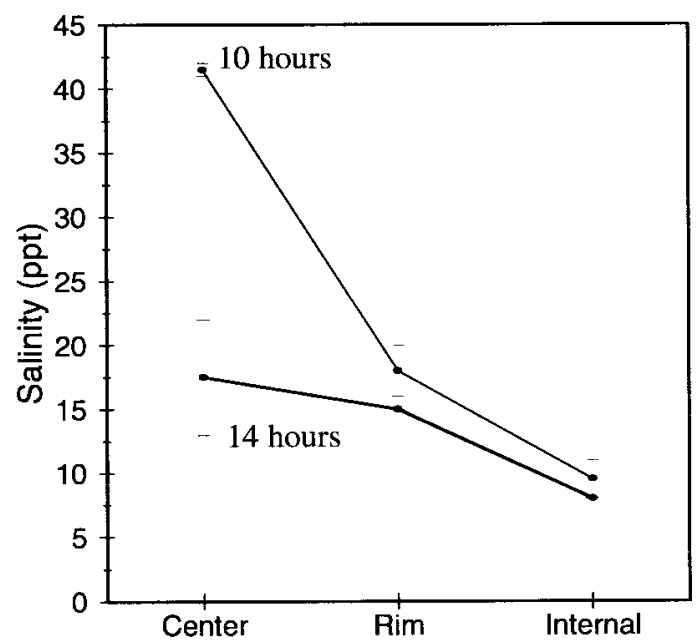

(c)

Fig. 10. (a) Salinity distribution history for various ice forms and at various pan locations. The pan salinities were acquired at a growth time of $14 \mathrm{~h}$. The ice sheet profile was taken after 13 days of growth. (b) The change in bulk salinity is shown. The salinity distribution for an ice pan depends on location, such as pan center, pan rim, or the internal portion of the pan. In (c), values obtained after 10 and $14 \mathrm{~h}$ of growth are shown.

Observations were made at wavelengths from 400 to $1000 \mathrm{~nm}$ under sunny skies for three pancake ice cases. The three cases studied include pans 3-h old, pans 7-h old, and an ice sheet 331-h old. The spectral albedo response for the three cases is shown in Fig. 12(a). The spectral response shapes for these three conditions are similar: a broad response positioned about the peak at about $550 \mathrm{~nm}$ and then a decay to a minimum at $1000 \mathrm{~nm}$. At a given wavelength, albedos show little spatial variability [see Fig. 12(b)]. Reflectances, however, are found to vary by as much as $50 \%$. Reflected light levels are the highest near $500 \mathrm{~nm}$ and the smallest at $1000 \mathrm{~nm}$ [see Fig. 12(c)].

In Fig. 12(d), a comparison is made of the albedo at $550 \mathrm{~nm}$ for ice grown under wave-agitated and quiescent [13] conditions. These observations include the following:

1) ice immediately after moderately sized pans have formed (age $=17 \mathrm{~h}$, January 11 a.m.);

2) when the pans congeal into an ice sheet (age $=20 \mathrm{~h}$, January 11 p.m.);

3) the ice sheet after 13 days of metamorphism and desalination (age $=330 \mathrm{~h}$, January 24 p.m.).
The albedo for ice with wave action is the lowest of the three cases cited. The pancake ice albedos are also about 26-39\% smaller that those of ice formed under quiescent conditions for the same ice thickness. This difference in albedo is significant. In the first pancake ice case, the low albedo is attributable to the mixture of water, slush and pans, and the high concentration of brine in the loosely congealed pan structure. In the second case, the pans have consolidated into an ice sheet, the slush in the gaps between the pans is freezing into an ice layer, and the pans are becoming more solid. This results in a $17 \%$ increase in albedo even though the ice thickness is about the same. The natural desalination process that occurs with the aging of ice over the next 13 days promoted the draining of brine from the ice sheet. This ice sheet presents an albedo that is $34 \%$ smaller than that of the congelation ice sheet.

\section{B. Passive Microwave Results at L- and S-Band}

Observation of microwave emission at 1.4-GHz (L-band) and 2.6- $\mathrm{GHz}$ (S-band) frequencies: $\mathrm{HH}$-polarization were car- 


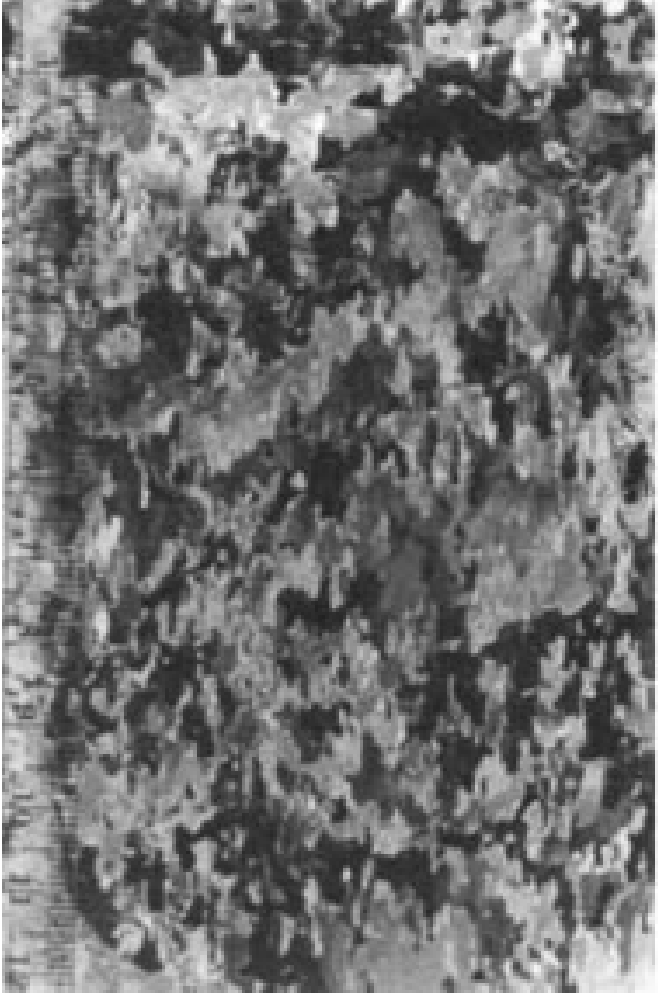

(a)

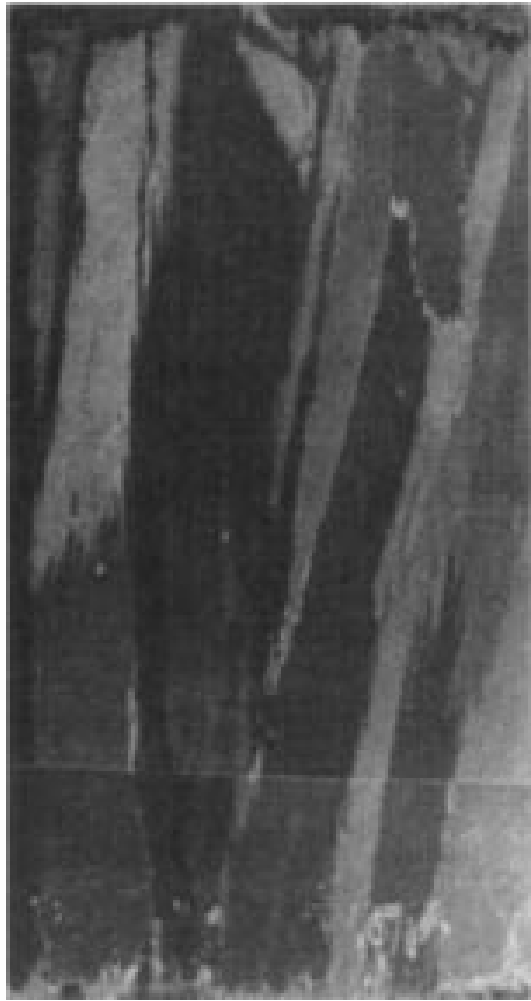

(b)

Fig. 11. Vertical thin section photographs of ice $12 \mathrm{~cm}$ thick, (a) composed of frazil and of pancake ice and (b) columnar ice grown under quiescent condition.

ried out at a $50^{\circ}$ nadir angle. This provides a means to penetrate within an ice layer to observe signature changes associated with ice thickness. The most dramatic change in radiometric signature is expected to occur during the early stages of ice growth. Observations for ice formed when conditions are calm and wave agitated are presented in Fig. 13. In the quiescent growth case, the change in emission level from open water to first-year ice is the most rapid at the shortest wavelength. The brightness temperature signatures at L- and S-band behave similarly until an ice thickness of about $0.6 \mathrm{~cm}$ (at about $30 \mathrm{~h}$ of experiment time), at this point the brightness temperature at S-band increases more rapidly.

At issue is the relative contribution of the bulk reflectivity of the top and bottom surfaces and how this changes with frequency. The surface reflectivity is always important, and the contribution of the bottom interface is determined by the attenuation factor (A), where $A=\exp (-4 \alpha l), \alpha$ is the absorption coefficient and $l$ is the geometrical path length through the ice layer. During the period described above, the bottom layer makes a critical contribution to the emission process, not just the surface reflectivity. Since the attenuation coefficient is inversely proportional to wavelength, it would be expected that the transition of the S-band signature to that of first-year ice will occur temporally more quickly than that of the L-band signature [14].

In the case of pancake ice formation, the L- and S-band signatures behave similarly throughout the entire pancake ice formation period, with occasional convergence-divergence in signature levels. The brightness temperature cases from 10.60 to 10.71 decimal days since January 1, 1995, are associated with open water and the formation of a thin, frazil ice skim. The brightness temperature experiences a level shift when wave action is applied at about 10.85 . Transitions and level shifts in brightness temperature are noted when slush forms $($ Decimal Day $=10.97)$ and ice clumps into pans (Decimal Day $=11.3$ ).

The dramatic difference between this response and that observed for congelation ice formation is attributable to the dynamics associated with constant wave agitation: a retarded freezing rate, an ice field that is not consolidated into a solid ice sheet, and a mixture of ice clumps or pans and slush during much of this formation period.

\section{Millimeter-Wave Radiometer Results}

Two commonly used ratios of brightness temperature $T_{B}$ include the GR and the PR. They are expressed as

$$
\begin{aligned}
G R & =\frac{T_{B}(37 \mathrm{~V})-T_{B}(18.7 \mathrm{~V})}{T_{B}(37 \mathrm{~V})+T_{B}(18.7 \mathrm{~V})} \text { and } \\
P R & =\frac{T_{B}(18.7 \mathrm{~V})-T_{B}(18.7 \mathrm{H})}{T_{B}(18.7 \mathrm{~V})+T_{B}(18.7 \mathrm{H})} .
\end{aligned}
$$

The brightness temperature $\left(\mathrm{T}_{B}\right)$ is related to the physical temperature through a scaling coefficient $\varepsilon$, the emissivity provided that the reflected sky radiation is taken into account. Results of millimeter wave radiometer measurements, made over a number of years (including 1995) at CRREL, are presented in Fig. 14. In Fig. 14(a), a comparison is made between the emission observed at two frequencies for the transition from open water to ice pans and is based on data collected during laboratory experiments conducted in 1994 and 


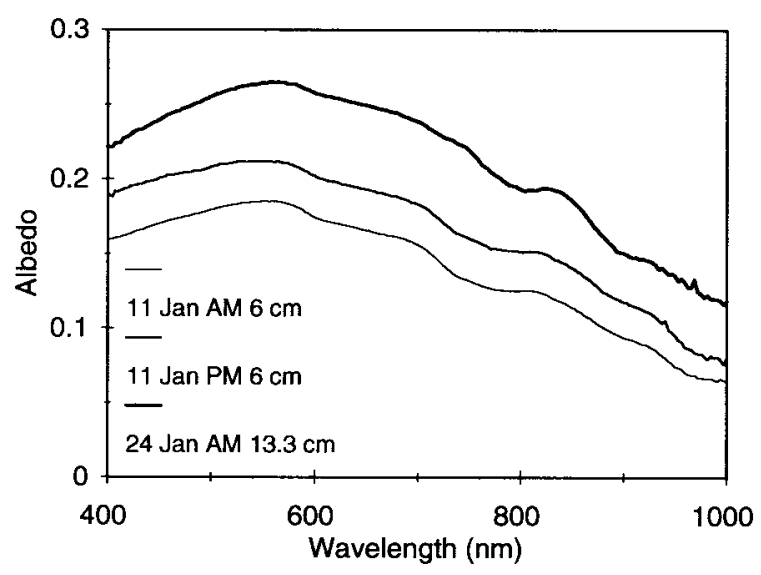

(a)

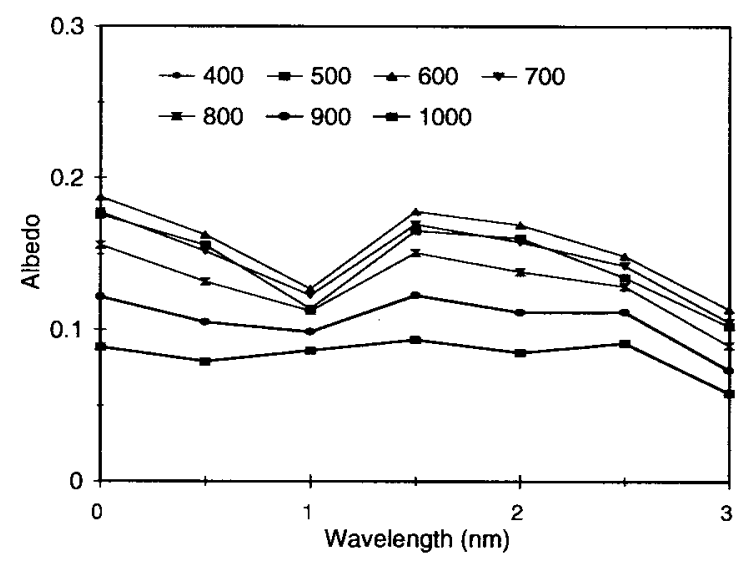

(c)

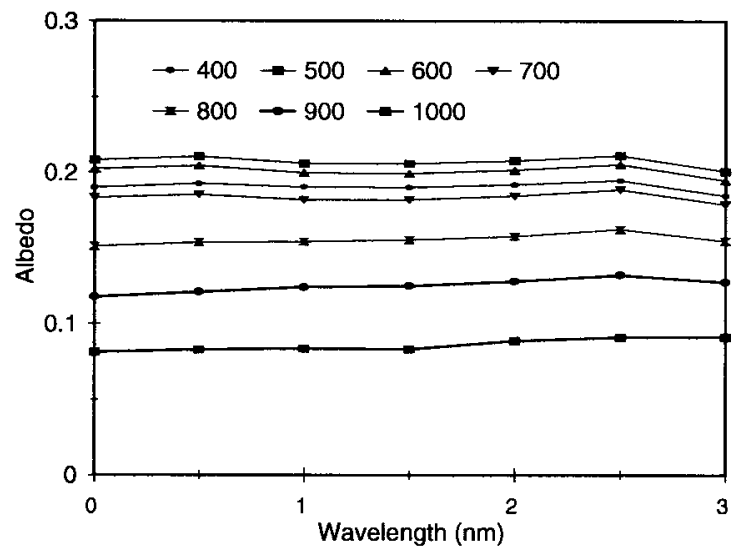

(b)

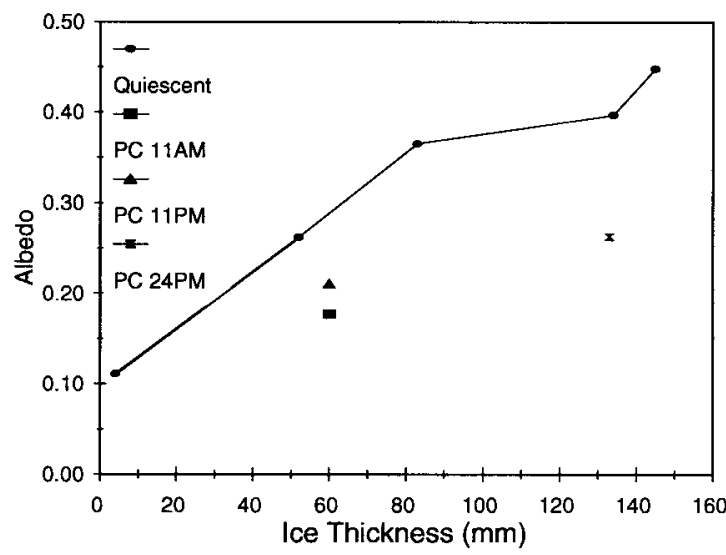

(d)

Fig. 12. Albedo is shown in (a) for wavelengths from 400 to $1000 \mathrm{~nm}$ for three periods during the formation of pancake ice. The data shown for January 11 are for when pans have formed and are consolidating. The data shown for January 24 are for the case of an ice sheet of pancake ice origin that has metamorphosed over more than a one-week period. In (b) and (c), the spatial variation in the albedo and nadir reflectance is shown for a field of pancakes that have consolidated and are congealing into an ice sheet. The surface of the pans is now frozen. Observations were made from 400 to $1000 \mathrm{~nm}$. A comparison of the albedo of ice grown under quiescent and wave action conditions at $550 \mathrm{~nm}$ is shown in (d).

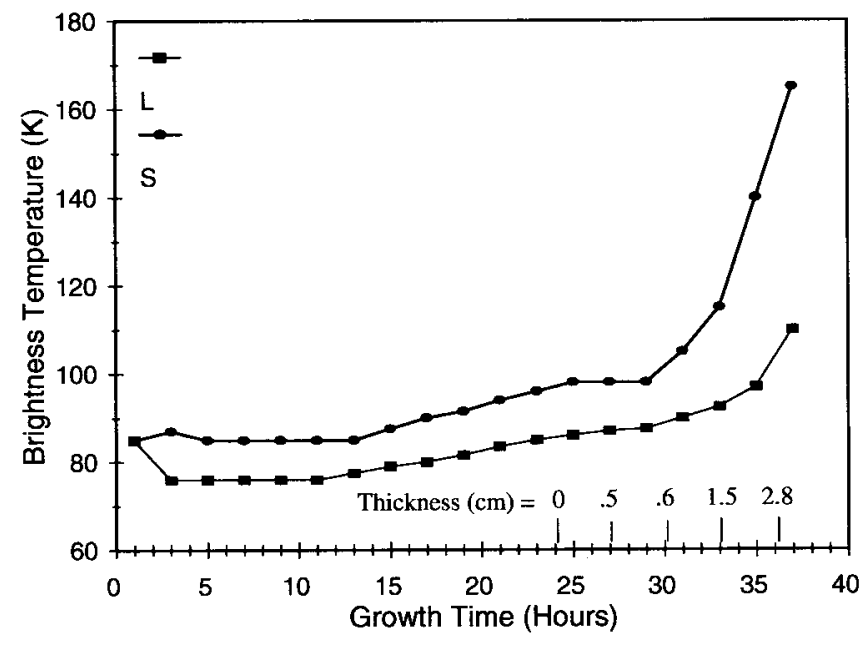

(a)

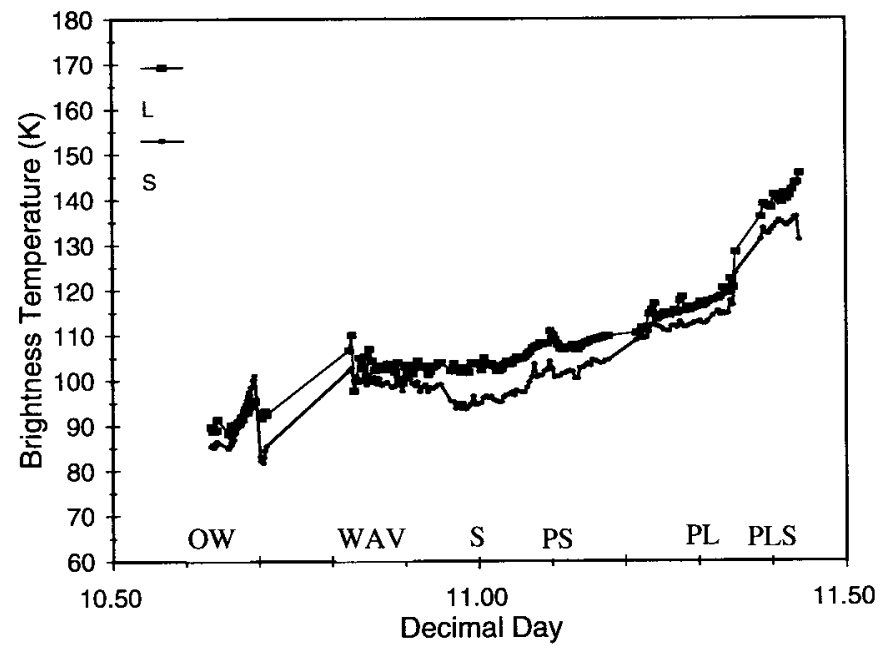

(b)

Fig. 13. Brightness temperature versus time at frequencies of $1.4 \mathrm{GHz}$ (L-band) and $2.6 \mathrm{GHz}$ (S-band) is shown for (a) quiescent and (b) wave-agitated growing conditions.

1995. The NASA team algorithm triangle that contains the composite signatures of all mixtures of open water, first-year ice, and multiyear ice used for the Defense Meteorological
Satellite Program Special Sensor Microwave Imager (SSM/I) is also shown. As newly formed ice thickens, a path toward that of first-year ice is expected. The prominent features that 


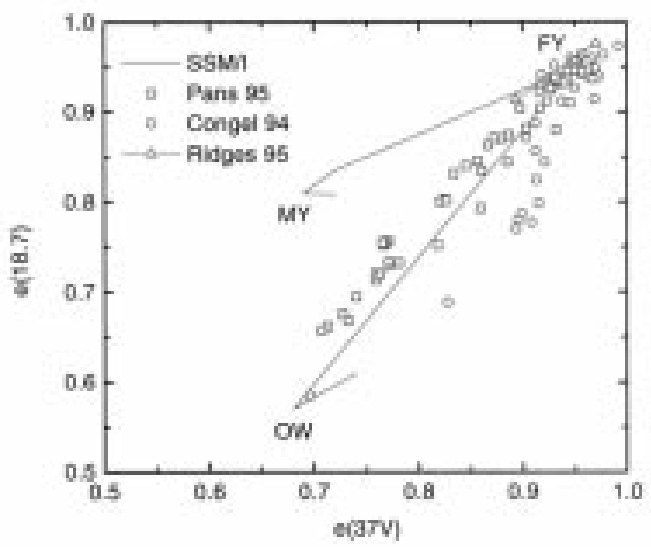

(a)

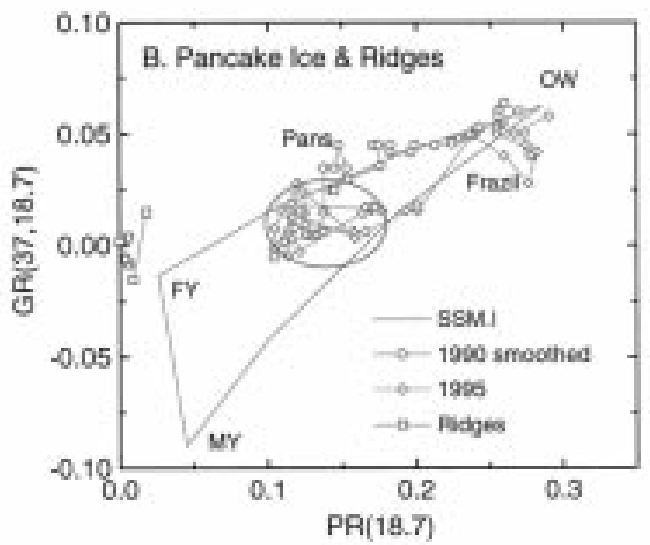

(c)

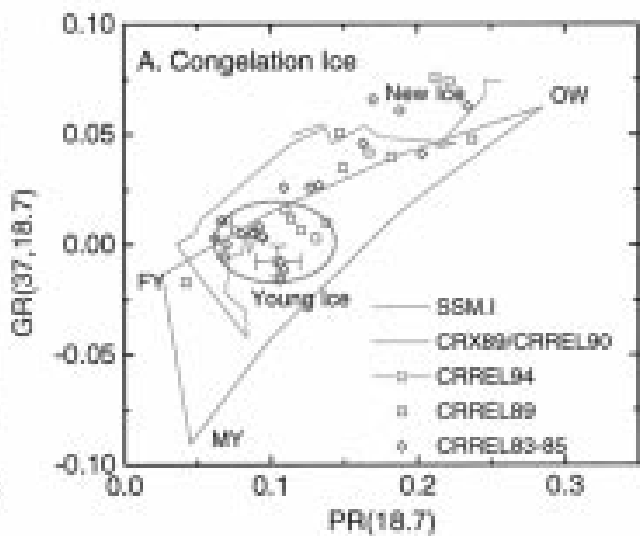

(b)

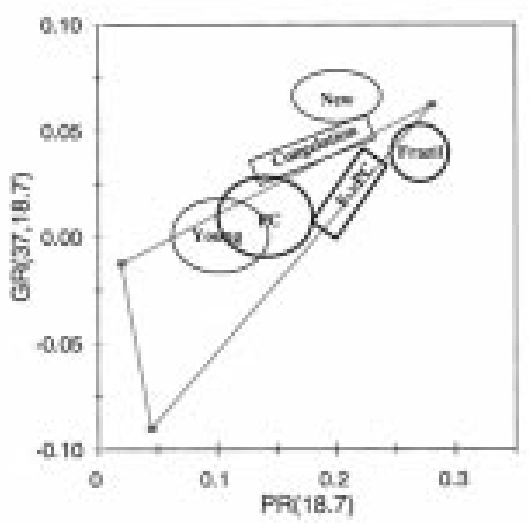

(d)

Fig. 14. (a) Emission GR and PR data are shown for (b) congelation, (c) pancake, and (c) frazil ice conditions and ridges. A comparison and summary diagram is made between the transition of ice with and without wave action based on change in gradient and PR's in (d).

arise from this intercomparison are that 1) the paths taken during the 1990 and 1995 investigations fall on different sides of the open water-first year line and 2) they converge when ice pans form. A critical difference between these two sets of observations is that pan formation may occur when ambient temperatures are warm (e.g., in 1990 temperatures range between -3 and $-10{ }^{\circ} \mathrm{C}$ ), or when conditions are cold (e.g., in 1995 temperatures range between -15 and $-23{ }^{\circ} \mathrm{C}$ ). Ambient temperatures at the marginal ice zone are equally variable. These results show that the temperature under which pan formation occurs is important in determining position on the PR-GR plot.

In Fig. 14(b) and (c), data collected at CRREL during 1989-1995 and during the CEAREX' 89 field study are used to show the transitions of ice grown under quiescent conditions and under wave action, respectively, which are shown in PR-GR space. In this mapping, new ice falls on the outside of the open water-first-year ice nomogram line, while frazil ice falls on the outside of the open water-multiyear nomogram line. The transition from new to first year for the congelation ice case continues to fall on the outside of the open water-firstyear nomogram line until young ice forms. When wave action is present and conditions are cold, the transition from water to ice pan formation follows the open water-multiyear line. The separation between the formation paths taken when conditions are calm or wave agitated is significant because of what it reveals about the electromagnetic emission process and the ability to invert signature information into ice property information. It is also important to note that ice that forms under quiescent conditions most often occurs when the ambient temperature is very cold. Warmer temperatures are associated with storms, hence with wind and wave conditions.

A summary figure is presented in Fig. 14(d) to show the difference between congelation and pancake ice formation for quiescent conditions. Ice form evolution follows a path from open water to new to congelation to young ice, while pancake ice follows the path from open water to frazil to frazil-to-pancake-to-pancake path. Note that throughout the aging process, quiescent and wave-agitated ice conditions take different paths in PR-GR space and that once the ice has thickened into young and pancake ice these ice forms map to different locations.

\section{Active Microwave Frequency}

Response for Pancake, Smooth, and Snow-Covered Ice: The frequency response for pancake ice, smooth thin ice, and 


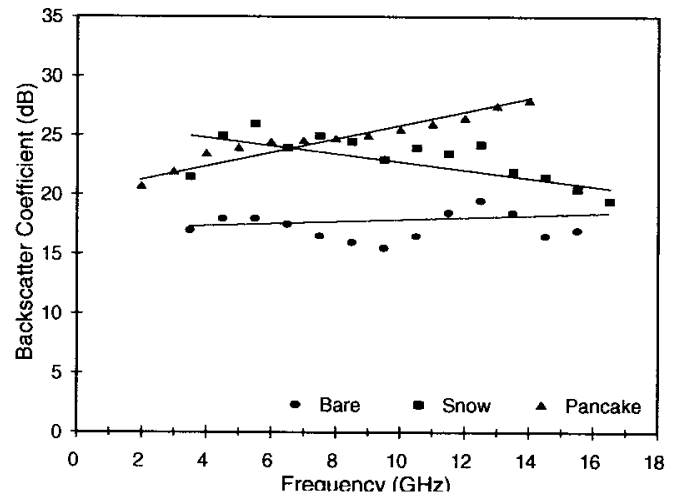

(a)

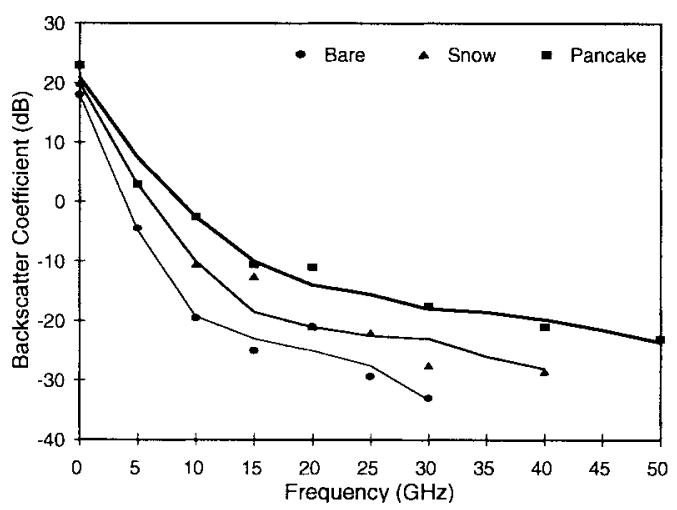

(c)

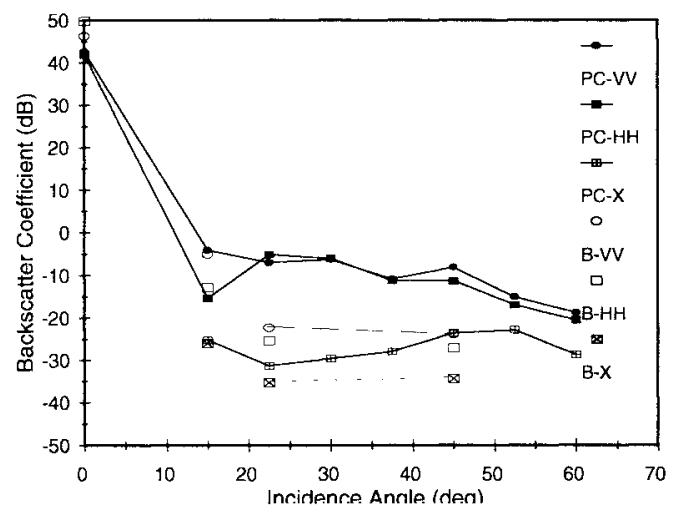

(e)

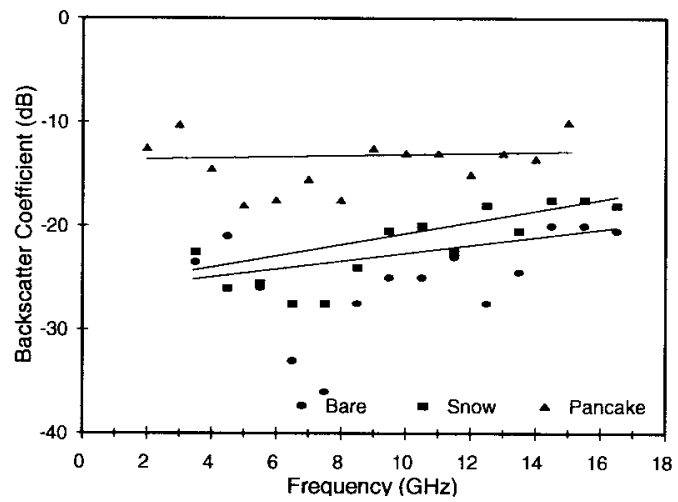

(b)

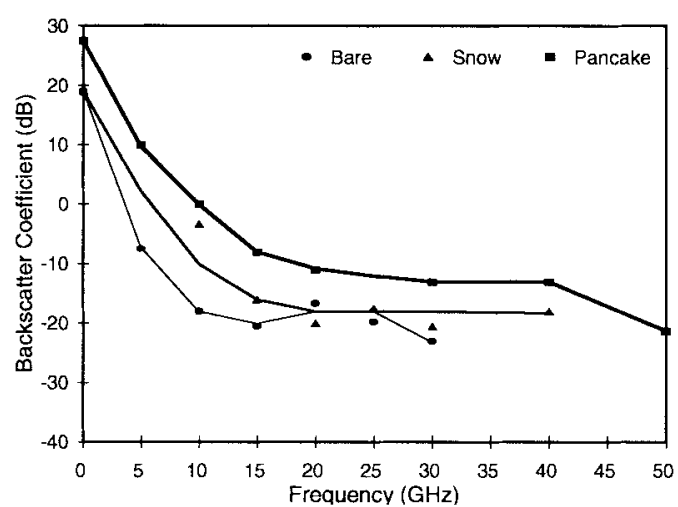

(d)

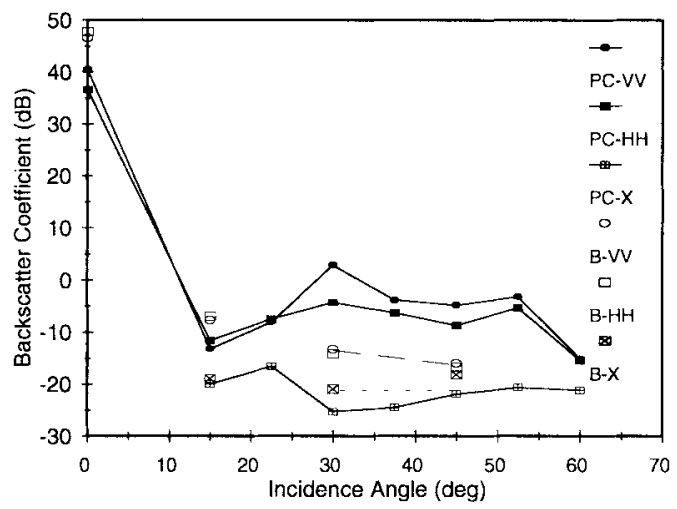

(f)

Fig. 15. Frequency response from 2 to $17 \mathrm{GHz}$ is shown at an incidence angle of (a) 0 and (b) $30^{\circ}$ for bare, snow-covered ice, and pancake ice. The angle response is also shown for (c) 5.3 , (d) 10 , (e) 14 , and (f) $38 \mathrm{GHz}$. The 5.3- and 14-GHz data are for VV-polarization.

snow-covered thin ice is shown in Fig. 15. In Fig. 15(a), the reflectivity response (backscatter measured at the $0^{\circ}$ nadir angle) is shown for frequencies from 2 to $16 \mathrm{GHz}$. Bare ice is included in this comparison because it makes a good reference from which to compare all other responses. Bare ice is structurally the most simple electromagnetic case. When bare ice is cold, its dielectric constant is small and its surface is smooth when compared to the other two cases. Both its backscatter and reflectivity responses are weak in comparison. The mean of the reflectivity response is approximately constant over this frequency range (at about $+17.5 \mathrm{~dB}$ ), and its fluctuation term is sinusoidal with an excursion of about $\pm 2 \mathrm{~dB}$.

Ice with a snow cover produces values 3-7.5 dB higher, but with a response that decreases with increasing frequency.
Snow cover is known to wick brine from the upper portion of the ice sheet, thereby raising the dielectric constant of the material at the snow-ice interface above that of bare ice. The reflectivity response is, thereby, dominated by the effective dielectric constant of the composite of the snow, slush, and ice layers. As the dielectric constant increases, the reflectivity increases. The greater the increase, the more brine has been wicked.

The key characteristic of pancake ice during the early formation period is its surface small-scale topography, the distribution of pan rims about a slightly rough pan center. Both the rims and pan centers are wet with seawater and brine; thus, their dielectric constant is approximately that of seawater when wave action is sufficient to build rims. The reflectivity 
response in this case is $4.5-10 \mathrm{~dB}$ greater than that of the bare ice surface, and its reflectivity values increase with increasing frequency. These data, however, suggest that discrimination between the reflectivities of snow-covered thin and pancake ice at frequencies between 4.5 and $9.5 \mathrm{GHz}$ will be difficult.

Reflectivity is proportional to the wavenumber squared, the power reflection coefficient, and surface roughness through an exponential term [15]. A perfectly smooth, level surface composed of seawater produces a reflectivity response that increases in value by $17 \mathrm{~dB}$ from 2 to $16 \mathrm{GHz}$ (see Fig. 16). However, when surface roughness increases, the frequency response changes. Sea ice that has grown under quiescent conditions has a minimum surface roughness value of about $0.05-\mathrm{cm} \mathrm{rms} \mathrm{[9],} \mathrm{the} \mathrm{change} \mathrm{in} \mathrm{reflectivity} \mathrm{over} \mathrm{this} \mathrm{frequency}$ range is $16.7 \mathrm{~dB}$. An rms roughness of $0.225 \mathrm{~cm}$ falls in the range measured for the pancake ice case and produces a reflectivity change of $7.5 \mathrm{~dB}$. A surface that is very rough $\left(\sigma_{s}=0.4 \mathrm{~cm} \mathrm{rms}\right.$ ) will cause the reflectivity to decrease dramatically with increasing frequency. The results shown in Fig. 15(a) also reinforce the observation that the wicking of brine into the snow layer produces an electrically rough interface. The reflectivity response for the snow case matches the shape of the response predicted for a very rough surface.

\section{E. Active Microwave Angle Response at $\mathrm{C}$-, $\mathrm{X}$-, $\mathrm{Ku}$-, and $\mathrm{Ka}$-Bands}

The frequency response at $30^{\circ}$ for bare, snow-covered, and pancake ice as observed from the wideband radar is shown in Fig. 15(b). Compared to bare ice, which shows the weakest mean intensity and backscatter levels that increase with increasing frequency, the snow-covered ice is 1.6-5.3 dB and the pancake ice is $9.0-13.7 \mathrm{~dB}$ greater in intensity. Part of this (potentially 6.5 to $5.5 \mathrm{~dB}$ ) is attributable to the difference in dielectric constant between the bare ice and the other two cases. The other prime contributor to the differences is effective surface roughness. Snow-covered ice wicks brine, but not uniformly, and presents a rough electrical slush-snow interface. In the case of pancake ice, the rims and pan centers produce a vertical height profile more rough than that of the bare ice case and a backscatter response that is an order-ofmagnitude greater. In this study case, the mean pancake ice response is found to be flat over the $2-16 \mathrm{GHz}$ frequency range, while the bare and snow-covered ice responses increase by about $6.5-12 \mathrm{~dB}$ over this frequency range.

Angle responses are shown for 5.3,10,14, and $38 \mathrm{GHz}$ in Fig. 15(c)-(f). At $5.3 \mathrm{GHz}(\mathrm{VV})$, it is shown that the pancake ice response is greater than that of bare and snow-covered ice at all angles. The separation is about $5-6 \mathrm{~dB}$ at $25^{\circ}$, and it increases further with increasing angle. At $14 \mathrm{GHz}(\mathrm{VV})$, the pancake ice response at $25^{\circ}$ is greater than that of bare and snow-covered ice by about $6-8 \mathrm{~dB}$. Again, the pancake ice response with angle is slowly decaying, an indication of a very rough surface, especially since the surfaces are wet with brine, which negates the contribution from volume scattering. At 10 and $38 \mathrm{GHz}$, responses are shown at VV-, $\mathrm{HH}-$, and X-polarizations for both pancake ice (filled symbols) and congelation ice (open symbols).

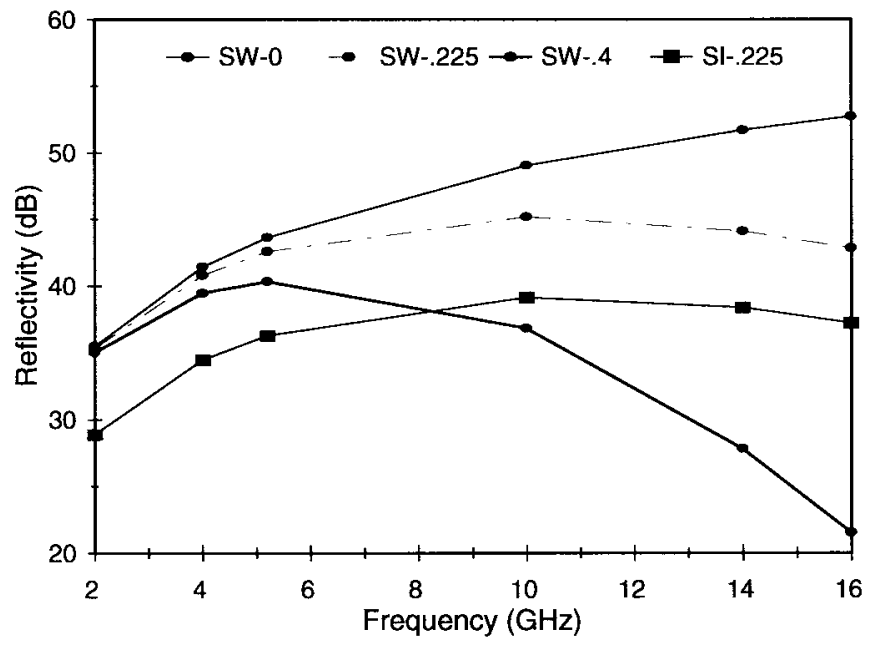

Fig. 16. Modeled reflectivity response for the frequency range from 2 to $16 \mathrm{GHz}$ for a surface with a dielectric constant similar to that of sea water (SW) and three surface roughness values (e.g., 0-, 0.225-, and 0.5-cm rms) and a surface with a dielectric constant (magnitude value $=5$ ) associated with young sea ice (SI), and an rms roughness (e.g., 0.225-cm rms) associated with pancake ice.

At $10 \mathrm{GHz}$, the increase in backscatter intensity at $25^{\circ}$ is about $18 \mathrm{~dB}$ at like polarization, but only $4 \mathrm{~dB}$ at cross polarization. The low cross-polarization difference suggests that the backscatter response for pancake ice is dominated by a pure surface scatter, there is some minimal rotation of the incoming electromagnetic wave by the geometry of the surface roughness elements, and that volume scattering is negligible. Because the ice material has a very high dielectric constant (both real and imaginary components), a pure surface scatter response is expected. The difference in the backscatter response at $\mathrm{VV}$ and $\mathrm{HH}$ is less in the pancake ice case than that for the bare ice sheet. This adds to the argument stated in the previous paragraph that the pancake ice sheet is very rough electromagnetically at this frequency. For ice sheets that are very smooth, the ratio of VV to $\mathrm{HH}$ is an indicator of the magnitude of the dielectric constant, in the sense that a large PR indicates a greater dielectric constant value [16].

At $38 \mathrm{GHz}$ and a $30^{\circ}$-nadir angle, the difference in the backscatter responses for pancake ice compared with congelation ice is about $13 \mathrm{~dB}$. Note that this is also the trend suggested in Fig. 15(b) that the contrast between pancake and bare ice decreases with increasing frequency, but remains large. The reduction at the $60^{\circ}$ angle may also be impacted by the reduction in pan size and rim height that occurred near the tank center.

\section{F. Comparison of the Active and Passive Microwave Temporal Responses}

The time evolution of emission and backscatter for the formation of pancake ice is shown in Fig. 17. This evolution begins with open water at its freezing point. Monitoring progress through the stages that include the application of waves energy, the formation of grease ice, the formation of slush, and the formation of pans. The various categories are time stepped by about $0.05-0.1$ day. Time steps within the same category are denoted by adding an integer to the ice form 
(e.g., S1 indicates the first time observation of the formation of slush, S2 indicates the second time observation of the formation of slush, but $0.05-0.1$ day later in time). In the case of the pan formation, $\mathrm{S}$ is used to indicate that the pans are small, L to indicate large pans, LS to indicate that the surface is freezing, IS to indicate that the ice sheet is congealing. Ice formation and environmental conditions are also summarized in Table II. The notation used in Fig. 17 is also included in this table.

The emission response is shown as a function of polarization in Fig. 17(a) and (b). Ambient air conditions are cold (e.g., at about $-20{ }^{\circ} \mathrm{C}$ ) for almost the entire ice formation process. Conditions warmed by about $5{ }^{\circ} \mathrm{C}$ by end of the formation period (PLS), but more significantly, snow flurries caused brine to wick onto the ice pans and form a 1-mm-thick slush layer (PL4). The change in emission from open water to the freezing together of pans into an ice sheet is almost monotonic. The emission varies more during the transition from slush to pans $(\mathrm{S} 3 \rightarrow \mathrm{PS})$. This fluctuation may be attributable to a reduction in emission associated with the development of a thickened slush layer (SL3), the enhancement in emission due to a secondary stage in slush development (SL2), or the initiation of pan formation (PS). An abrupt signature modification is observed for the pancake ice sheet when a thin slush layer forms in association with the accumulation of snow associated with a brief period of light snow flurries (PL5). This reduction in emission is significant at both polarizations, but does not return to the emission associated with open water; it more closely matches values associated with grease and slush ice conditions. The time-evolution response shown stops with the metamorphosed ice sheet $12 \mathrm{~cm}$ thick. The emission is the highest of any of the many stages, except at 37 and $90 \mathrm{GHz}$ and $\mathrm{H}$-polarization, where values are similar to the large pan cases. An important spectral characteristic of the thick ice sheet case is the convergence in emissivity value at the different wavelengths to a narrow range of values, about 0.93 for VV-polarization, and 0.73 for $\mathrm{HH}$-polarization. There is still a sizable difference from the emission response for standard thick, first-year ice. Emission values for firstyear ice vary between $0.92-0.95$ and $0.84-0.90$ for VV- and $\mathrm{HH}$-polarization, respectively.

The backscatter response is shown in Fig. 17(c)-(e) for frequencies of 5.3,10.0, and $38.0 \mathrm{GHz}$ for an incidence angle of $35^{\circ}$ and polarizations of $\mathrm{VV}, \mathrm{HH}$, and $\mathrm{X}$. The time-evolution behavior is strongly influenced by the operating frequency. At $5.3 \mathrm{GHz}$, there is a reduction in backscatter from that of open water. This reduction is also observed for quiescent growth conditions. Even though the wind conditions were calm, even the slightest breeze is sufficient to produce a wind roughening of the water surface and a backscatter enhancement over that of a smooth saline surface. The backscatter level continues to decay through the final stage of slush formation. The weakest backscatter response is associated with a thick slush layer.

Once pans begin to form, the backscatter intensity increases rapidly and at all polarizations. The peak backscatter conditions are associated with the full formation of the pan field and the initiation of freezing of the pan surfaces (PLS). The pancake ice response achieves levels $15 \mathrm{~dB}$ greater than those
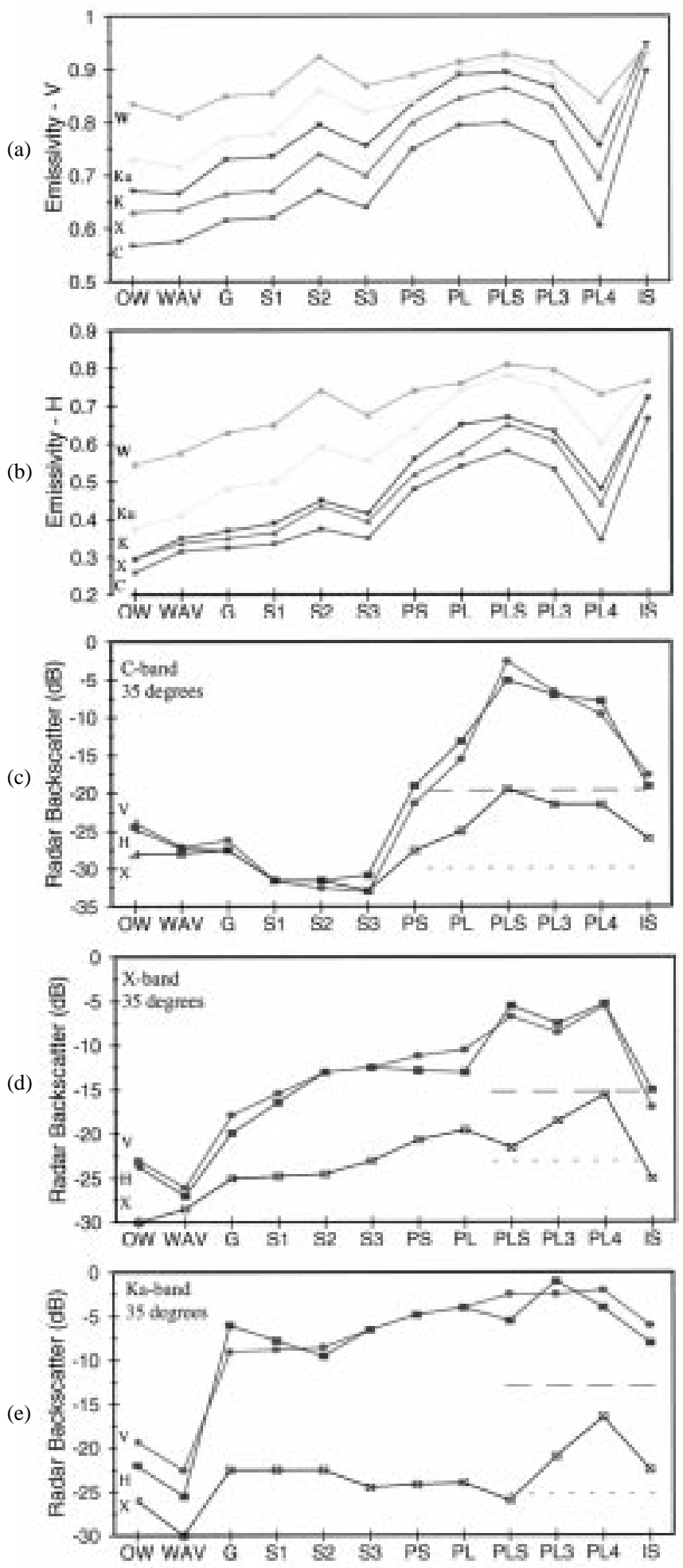

Fig. 17. Active and passive microwave responses for the time evolution from calm (OW) and wavy (WAV) open water, and the formation of grease ice (G), slush (S), pans (P), and an ice sheet (IS). Small pans are indicated with $S$, large pans with L, and pan with frozen surfaces with LS. The numbers indicate increments in decimal day between 0.1 and 0.05 day. The horizontal lines in the active microwave responses indicate like- (dashed) or cross- (dotted) polarization responses for ice grown under quiescent conditions.

of young congelation ice. In the backscatter case, the wicking of brine by the light snow flurry event is much less dramatic than was the case for emission. 
At $10.0 \mathrm{GHz}$, the major change in backscatter intensity begins once grease ice forms. The change in backscatter intensity continues monotonically through the final pancake ice formation state and results in backscatter enhancement of about $17-20 \mathrm{~dB}$ above that of calm sea water. The pancake ice response is also about $15 \mathrm{~dB}$ greater than that of young congelation ice.

At $38 \mathrm{GHz}$, a dramatic increase in backscatter intensity is found to occur once grease ice formation begins, and the temporal response continues to increase monotonically. The shift from wave-agitated water to grease-ice laden water waves is about $12.5 \mathrm{~dB}$ and to an ice sheet composed of pans is about $19 \mathrm{~dB}$. The difference in the like-polarization response for pancake and congelation ice is about $10 \mathrm{~dB}$. For these three frequency cases and at this incidence angle, the difference between VV- and HH-polarizations is typically very small.

\section{SUMMARY}

The first interdisciplinary and integrated approach to the investigation of the electromagnetic properties of sea ice formed in the presence of waves has been completed. A database of observations over a wide spectral range and for various sensor modes has been assembled. Temporal and formation variability associated with the transformation of ice into different forms (e.g., open water, frazil, grease, slush, pancake, and consolidated ice) has been documented. Integrated measurements of the type described here bound the type of electromagnetic processes that may be occurring. These data also provide an important resource from which to develop and validate forward and inverse scattering models and satellite algorithms. The knowledge that propagation and scattering is sensitive to different layers and particle sizes based on the scale of the wavelength presented the anticipation that a "broad spectral" analysis has merit that includes "data fusion" and "broad spectral analysis."

The important results produced by this study are made more revealing when compared to the differences between the ice signatures that are produced during wave-agitated or quiescent conditions. These include the following.

1) The formation conditions produce a separation in the albedos of young sea ice.

2) The separation and rate of change with growth time in brightness temperature at L- and S-band frequencies allows the discrimination between ice forms produced under wave-agitated (e.g., linear change) or quiescent (nonlinear change) conditions.

3) In PR-GR space, the transformation from open water to young ice takes distinctly different paths for waveagitated or quiescent conditions. The location of young ice is also impacted.

4) Surface roughness and dielectric constant may be retrieved based on the acquisition of a wideband reflectivity response.

5) The active microwave behavior suggests strongly that temporal monitoring at multiple frequencies will yield considerable information as to the thickness and profile properties of the evolving ice field.
6) Backscatter is observed to be less sensitive than emission to temporary modifications of the ice surface to influences that cause brine expulsion (i.e., snow flurries).

\section{ACKNOWLEDGMENT}

The assistance of J. Govoni and B. Elder in the experiment is gratefully acknowledged.

\section{REFERENCES}

[1] S. D. Smith, R. D. Muench, and C. H. Pease, "Polynyas and leads: An overview of physical processes and environment," J. Geophys. Res., vol. C3, pp. 4675-4689, 1991.

[2] T. C. Grenfell, D. J. Cavalieri, J. C. Comiso, M. R. Drinkwater, R. G. Onstott, I. Rubinstein, K. Steffen, and D. P. Winebrenner, "Considerations for remote sensing of thin sea ice," Microwave Remote Sensing of Sea Ice, F. Carsey, Ed. Washington, DC: Amer. Geophys. Union, 1992, pp. 291-300.

[3] C. H. Pease, "The size of wind driven coastal polynyas," J. Geophys. Res., vol. 92, pp. 7049-7059, 1987.

[4] K. Steffen, "Ice conditions of an Arctic polynya," J. Glaciology Res., vol. 32, pp. 383-340, 1986

[5] P. Wadhams, J. Comiso, E. Prussen, S. Wells, M. Brandon, E. Aldworth, T. Viehoff, R. Allegrino, and D. Crane, "The development of the Odden ice tongue in the Greenland Sea during winter 1993 from remote sensing and field observations," J. Geophys. Res., vol. 101, no. 18, pp. 18213-18 235, 1996.

[6] WMO Sea Ice Nomenclature. Geneva, Switzerland: Secretariat of the World Meteorol. Org., 1970.

[7] W. B. Tucker, T. C. Grenfell, R. G. Onstott, D. K. Perovich, A. J. Gow, R. A. Shuchman, and L. L. Sutherland, "Microwave and physical properties of sea ice in the winter marginal ice zone," J. Geophys. Res., vol. 96, no. C3, pp. 4573-4587, 15 Mar. 1991.

[8] P. Wadhams and B. Holt, "Waves in frazil and pancake ice and their detection on Seasat SAR imagery," J. Geophys. Res., vol. 96, pp. 8835-8852, May 1991.

[9] R. G. Onstott, "SAR and scatterometer signatures of sea ice," Microwave Remote Sensing of Sea Ice, F. D. Carsey, Ed. Washington, DC: Amer. Geophys. Union, 1992, pp. 73-87.

[10] C. T. Swift, K. St. Germain, K. C. Jezek, P. Gogineni, A. J. Gow, D. K Perovich, T. C. Grenfell, and R. G. Onstott, "Laboratory investigations of the electro-magnetic properties of artificial sea ice," Microwave Remote Sensing of Sea Ice, F. Carsey, Ed. Washington, DC: Amer. Geophys. Union, 1992, pp. 177-199.

[11] E. Bennet, E. J. Knapp, and C. T. Swift, "Low frequency microwave radiometer observations of saline ice," in Proc. IEEE Geosci Remote Sensing Symp., 1995

[12] D. T. Eppler, M. R. Anderson, D. J. Cavalieri, J. Comiso, L. D. Farmer C. Garrity, P. Gloersen, T. C. Grenfell, M. Hallikainen, A. W. Lohanick, C. Maetzler, R. A. Melloh, I. Rubinstein, and C. T. Swift, "Passive microwave signatures of sea ice," Microwave Remote Sensing of Sea Ice, F. Carsey, Ed. Washington, DC: Amer. Geophys. Union, 1992, pp. 47-68.

[13] T. C. Grenfell, D. G. Barber, A. K. Fung, A. J. Gow, K. C. Jezek, E. J. Knapp, S. V. Nghiem, R. G. Onstott, D. K. Perovich, C. S. Roesler, C. T. Swift, and F. Tanis, "Evolution of electromagnetic signatures of sea ice from initial formation to the establishment of thick first-year ice," this issue, pp. 1642-1654.

[14] K. St. Germain, C. T. Swift, and T. C. Grenfell, "Determination of the dielectric constant of young sea ice using spectral radiometry," $J$. Geophys. Res., vol. 98, no. C3, pp. 4675-4679, 1993.

[15] F. T. Ulaby, R. K. Moore, and A. K. Fung, Microwave Remote Sensing, vol. II. Reading, MA: Addison-Wesley, 1982, pp. 938.

[16] M. R. Drinkwater, R. Kwok, E. Rignot, H. Israelsson, R. G. Onstott, and D. P. Winebrenner, "Potential applications of polarimetry to the classification of sea ice," Microwave Remote Sensing of Sea Ice, F. Carsey, Ed. Washington, DC: Amer. Geophys. Union, 1992, pp. 419-430.

Robert G. Onstott (S'73-M'79), photograph and biography not available at the time of publication. 
Prasad Gogineni (S'75-M'76-SM'91), photograph and biography not available at the time of publication.

Anthony J. Gow, for a photograph and biography, see p. 124 of the January 1998 issue of this TRANSACTIONS.

Thomas C. Grenfell (M'94-A'95), for a photograph and biography, see p. 124 of the January 1998 issue of this TRANSACTIONS.
Kenneth C. Jezek (A'92), photograph and biography not available at the time of publication.

Donald K. Perovich, for a photograph and biography, see p. 124 of the January 1998 issue of this TRANSACTIONS.

C. T. Swift (M'67-SM'69-F'83), photograph and biography not available at the time of publication. 